\title{
Integrin-Linked Kinase Regulates Process Extension in Oligodendrocytes via Control of Actin Cytoskeletal Dynamics
}

\author{
Ryan W. O’Meara, ${ }^{1,2 \star}$ John-Paul Michalski, ${ }^{1,2 \star}$ Carrie Anderson, ${ }^{1,2}$ Kunal Bhanot, ${ }^{1,2}$ Peter Rippstein, ${ }^{4}$ \\ and Rashmi Kothary ${ }^{1,2,3}$ \\ ${ }^{1}$ Ottawa Hospital Research Institute, Ottawa, Ontario K1H 8L6, Canada, Departments of ${ }^{2}$ Cellular and Molecular Medicine and ${ }^{3}$ Medicine, University of \\ Ottawa, Ottawa, Ontario K1H 8M5, Canada, and ${ }^{4}$ Lipoproteins and Atherosclerosis Group, University of Ottawa Heart Institute, Ottawa, Ontario K1Y 1V1, \\ Canada
}

Integrin-linked kinase (ILK) is a major structural adaptor protein governing signaling complex formation and cytoskeletal dynamics. Here, through the use of conditional knock-out mice, we demonstrate a requirement for ILK in oligodendrocyte differentiation and axonal myelination in vivo. In conjunction, ILK-deficient primary oligodendrocytes are defined by a failure in process extension and an inability to form myelin membrane upon axonal contact. Surprisingly, phosphorylation of the canonical downstream targets Akt and GSK3 $\beta$ is unaffected following ILK loss. Rather, the defects are due in part to actin cytoskeleton dysregulation with a correspondent increase in active RhoA levels. Morphological rescue is possible following Rho kinase inhibition in an oligodendrocyte subset. Furthermore, phenotypic severity correlates with environmental complexity; oligodendrocytes are severely malformed in vitro (a relatively simple environment), but undergo phenotypic recovery in the context of the whole animal. Together, our work demonstrates ILK as necessary for normal oligodendrocyte development, reinforces its role as a bridge between the actin cytoskeleton and cell membrane, and highlights the overarching compensatory capacity of oligodendrocytes in response to cellular milieu.

\section{Introduction}

During development, oligodendrocyte precursor cells (OPCs) differentiate into oligodendrocytes (OLs) that extend processes to contact multiple axons of CNS neurons. The process of myelination is controlled in part by cell extrinsic factors derived from the extracellular matrix (ECM). Laminin-2 (Ln-2) is an ECM component with high relevance to OL-mediated myelination of the CNS (O'Meara et al., 2011a). Ln-2 is deposited in developing axonal tracts (Colognato et al., 2002), providing a ligand for the $\alpha 6 \beta 1$ integrin receptor expressed by OLs. The $\beta 1$ integrin subunit was shown previously to regulate OL process extension in vitro (Buttery and ffrench-Constant, 1999; Relvas et al., 2001; Liang et al., 2004; Barros et al., 2009) and myelination in vivo (Relvas et al., 2001; Lee et al., 2006; Barros et al., 2009; Câmara et al., 2009). In light of these findings, precisely how $\beta 1$ integrin

Received Dec. 6, 2012; revised April 9, 2013; accepted April 28, 2013.

Author contributions: R.W.O., J.-P.M., and R.K. designed research; R.W.O. and J.-P.M. performed research; C.A. K.B., and P.R. contributed unpublished reagents/analytic tools; R.W.O., J.-P.M., and P.R. analyzed data; R.W.O., J.-P.M., and R.K. wrote the paper.

This work was supported by a grant from the Multiple Sclerosis Society of Canada. J.-P.M. and R.W.O. are recipients of Frederick Banting and Charles Best Canadian Institutes of Health Research Doctoral Research Awards, and R.K. is a recipient of a University Health Research Chair from the University of Ottawa. We thank Andrew Ferrier and Dr. Lyndsay Murray for comments on this manuscript, and the rest of the Kothary laboratory for helpful discussions. We also thank Dr. Brian Popko, Dr. Rene St-Arnaud, and Dr. Steffany Bennett for generous donations of transgenic mice.

${ }^{*}$ R.W.O. and J.P.M. contributed equally to this work.

The authors declare no competing financial interests.

This article is freely available online through the J Neurosci Author Open Choice option.

Correspondence should be addressed to Rashmi Kothary, Ottawa Hospital Research Institute, 501 Smyth Road, Ottawa, Ontario K1H 8L6, Canada. E-mail: rkothary@ohri.ca.

DOI:10.1523/JNEUROSCI.5582-12.2013

Copyright $\odot 2013$ the authors $\quad 0270-6474 / 13 / 339781-13 \$ 15.00 / 0$ transduces ECM cues via signaling intermediates, and the mechanism by which this translates to cellular responses, need to be addressed.

Integrin-linked kinase (ILK), a focal adhesion protein, binds to the cytosolic $\mathrm{C}$ terminus of $\beta 1$ integrin (Hannigan et al., 1996) and mediates signaling between the ECM and the cellular interior. ILK is composed of three domains, an N-terminal ankryin domain, a pleckstrin homology domain, and a putative kinase domain. ILK forms an obligate heterotrimeric complex with particularly interesting Cys-His-rich protein (PINCH) and parvin, which together lend stability to the actin cytoskeleton at focal adhesions (Brakebusch and Fässler, 2003). This function is likely mediated through additional signaling proteins, such as paxillin and PAK-interacting exchange factor (PIX), ultimately impacting on actin modulator proteins via Rho GTPases (Rosenberger et al., 2003).

In this study, we sought to investigate the role of ILK in OL differentiation and myelination of the CNS. By ablating ILK from cultured OPCs, we show that it is important for their molecular and morphological differentiation. Conditional ILK loss in postnatal mice results in amyelination of optic nerve axons, an effect that is compensated for at later time points. There is evidence of a bonafide kinase function for ILK (for review, see Hannigan et al., 2011); however, we did not observe any changes in the phosphorylation status of its canonical targets GSK3 $\beta$ and Akt in ILKdepleted OLs. Rather, we observe an increase in active RhoA levels as a result of ILK loss, a phenomenon associated with actin cytoskeletal defects. Interestingly, pharmacological manipulation of the RhoA pathway is able to rescue aberrant morphology of a distinct population of ILK-deficient OLs. Our data indicate 
an important role for ILK in OL development and myelination of the CNS, which, in turn, is linked to regulation of the actin cytoskeleton. Understanding OL differentiation will be important for rectifying or circumventing myelinating diseases such as multiple sclerosis, where demyelinated lesions are characterized by stalled premyelinating OLs (Chang et al., 2002).

\section{Materials and Methods}

Transgenic and reporter mice. The mice used in this work were cared for according to Canadian Council on Animal Care guidelines. Ethical approval for experiments conducted was obtained from the University of Ottawa Animal Care Committee under protocol number OGH-119. Ilk ${ }^{f l f l}$ and $P l p-C r e E R^{T}$ mice were provided by Dr. René St-Arnaud, McGill University, Montreal, Canada (Terpstra et al., 2003) and Dr. Brian Popko, University of Chicago, Chicago, IL (Doerflinger et al., 2003), respectively. Two mouse strains were primarily used for experiments: $I l k^{f l / f l} ; \mathrm{Plp}-\mathrm{CreER}^{T} /+$ mice (Ilk $c K O$ ) and $I l k^{f l f l} ;+/+$ [wild-type (WT)] littermate controls. An injection of $0.375-0.5 \mathrm{mg}$ of tamoxifen ( 7.5 or $10 \mu \mathrm{l}$ of a 50 $\mathrm{mg} / \mathrm{ml}$ solution, respectively) was administered to postnatal day 4 (P4) pups to induce recombination. For the low-dose tamoxifen experiments, $\mathrm{P} 4$ mice were given a single $10 \mu \mathrm{l}$ injection from a $2 \mathrm{mg} / \mathrm{ml}$ tamoxifen solution to induce minimal recombination. Ilk $c K O$ mice were crossed to a floxed stop tdTomato-EGFP $(m T / m G)$ reporter line (Muzumdar et al., 2007) to generate Ilk $k^{f l / f l} ; P l p-C r e E R^{T} /+; m T / m G$ (Ilk $c K O ; m T / m G$ ) mice, which were bred to homozygosity for the reporter transgene. Mice of either sex were used for all experiments.

Cell culture. OL cultures and OL/dorsal root ganglion neuron (DRGN) cocultures were derived as described previously (O'Meara et al., 2011b). For Rho kinase (ROCK) inhibition, compound Y-27632 $\left(\mathrm{C}_{14} \mathrm{H}_{21} \mathrm{~N}_{3} \mathrm{O}\right)$ was added to each well at a final concentration of $10 \mu \mathrm{M}$ daily for $6 \mathrm{~d}$. For control wells, an equal volume of water (vehicle) was added.

Immunohistochemistry. Cell culture coverslips were fixed with $100 \%$ methanol at $-20^{\circ} \mathrm{C}$ for $10 \mathrm{~min}$ or $3 \%$ paraformaldehyde (PFA) at room temperature for $15 \mathrm{~min}$. Coverslips were then washed with PBS, permeabilized with $0.1 \%$ Triton X-100 solution, blocked with $10 \%$ goat serum (GS), and incubated with primary antibodies against myelin-associated glycoprotein (MAG; EMD Millipore), myelin basic protein (MBP; AbD Serotec), CC1 (Abcam), green fluorescent protein (GFP; Invitrogen), neurofilament-200 (NF-200; Sigma-Aldrich), cleaved caspase 3 (Asp175; Cell Signaling Technology), 5-bromo-2'-deoxyuridine (BrdU; BD Biosciences), and NG2 (EMD Millipore) in blocking solution at $4^{\circ} \mathrm{C}$ overnight. Coverslips were then washed with PBS and incubated with Alexa Fluor-conjugated secondary antibodies (Alexa-488, Alexa-555, Alexa647; Invitrogen) and/or rhodamine phalloidin (Invitrogen). Samples were then counterstained with 4',6-diamidino-2-phenylindole (DAPI) and mounted in Dako mounting medium.

For immunohistochemistry of murine tissue, mice were anesthetized with tribromoethanol (Avertin) and perfused transcardially with $4 \%$ PFA. Optic nerves were dissected in PBS and postfixed overnight in $4 \%$ PFA at $4^{\circ} \mathrm{C}$ followed by overnight cryopreservation in $30 \%$ sucrose/PBS at $4^{\circ} \mathrm{C}$ and then embedded in a $1: 1$ mixture of $30 \%$ sucrose/OCT (Sakura). Briefly, $10 \mu \mathrm{m}$ sections were washed with PBS followed by a 10-30 min incubation in citrate buffer ( $10 \mathrm{~mm}$ citric acid, $26 \mathrm{~mm} \mathrm{NaOH}$, pH 6) for certain antibodies. Sections were blocked in either 10\% GS with
B
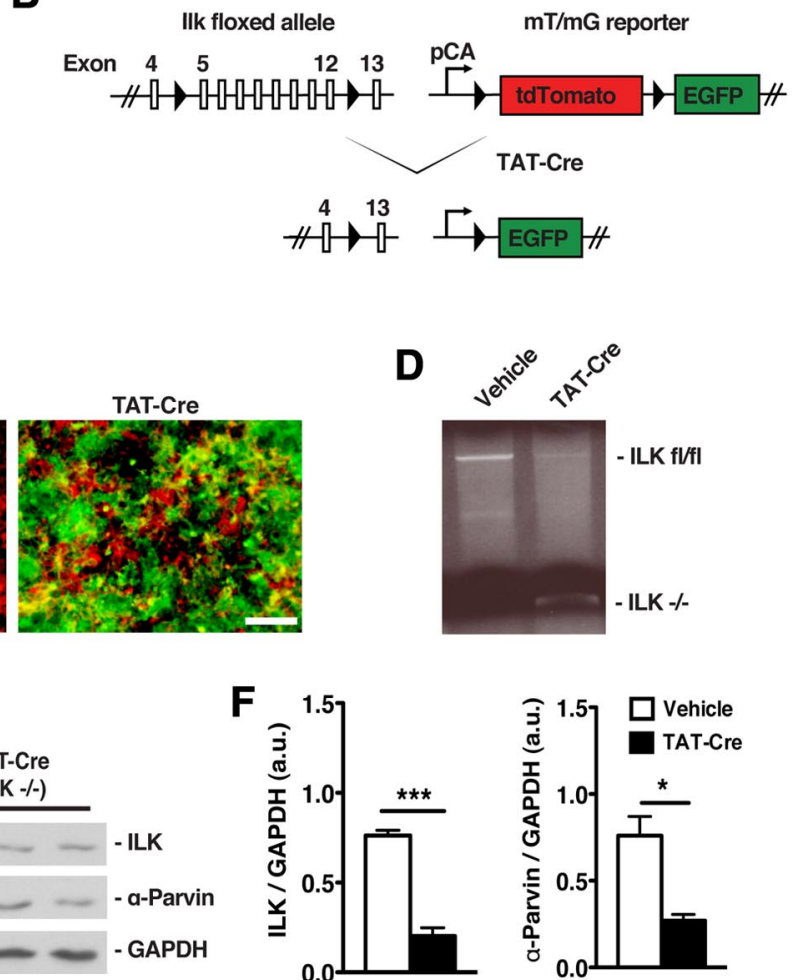

Figure 1. Genetic ablation of ILK from primary glial cells. $A$, Western blot analysis of ILK and $\alpha$-parvin in primary murine 0 Ls at graphed glial cultures derived from $I / k^{t / f} ; m T / m G$ mice treated with vehicle or TAT-Cre. D, PCR performed on DNA isolated as control for toxicity. $\boldsymbol{F}$, Densitometry analysis of Western blots in $\boldsymbol{E}$ for ILK and $\alpha$-parvin between TAT-Cre- and vehicle-treated cultures. Data represent the mean $\pm \operatorname{SEM}(n=3) .{ }^{*} p<0.05 ;{ }^{* * *} p<0.001$ (Student's $t$ test). Scale bar, $100 \mu \mathrm{m}$.

$1 \%$ BSA and $0.2 \%$ Triton X-100 or TBLS (0.5 mm Tris- $\mathrm{HCl} \mathrm{pH} 7.4$, $0.0085 \% \mathrm{NaCl}, 0.01 \% \mathrm{BSA}, 0.009 \%$ L-lysine, and $10 \%$ sodium azide) with $20 \%$ GS and $0.3 \%$ Triton X-100 for $1 \mathrm{~h}$. Primary antibodies were diluted in either $1 \%$ GS with $1 \%$ BSA and $0.2 \%$ Triton X-100 or TBLS with $20 \%$ GS and $0.3 \%$ Triton X-100 and placed on sections overnight at $4^{\circ} \mathrm{C}$. Sections were then washed and incubated with Alexa Fluor conjugated secondary antibodies (Invitrogen) in the same solution as primary antibodies. Sections were counterstained with DAPI and mounted in Dako mounting medium.

BrdU labeling. DIV2 OL cultures were pulsed with $\sim 20 \mathrm{~nm}$ of BrdU for $4 \mathrm{~h}$ and subsequently fixed with $3 \%$ PFA at room temperature for $15 \mathrm{~min}$. Coverslips were washed in PBS, permeabilized with $0.1 \%$ Triton X-100 solution, and treated with $2 \mathrm{~N} \mathrm{HCl}$ for $20 \mathrm{~min}$ on a rotary shaker. Samples were then topped up with an equal volume of $0.1 \mathrm{M}$ Tris- $\mathrm{HCl}, \mathrm{pH} 9.5$, and incubated on the rotary shaker for an additional $20 \mathrm{~min}$. Samples were then stained with anti-BrdU antibody using the same method as described above.

Whole-mount immunohistochemistry. Mice were anesthetized with Avertin and killed at either P14 or P28. The optic nerve was immediately removed and placed in a 4\% PFA solution for $1 \mathrm{~h}$ at room temperature with gentle agitation. The nerve was then washed in PBS followed by a 30 min incubation in $2 \%$ Triton X-100 and blocked in a $4 \%$ BSA, $1 \%$ Triton $\mathrm{X}-100$ solution. The optic nerve was then incubated overnight with an antibody against GFP in blocking solution. The next day, an Alexa Fluorconjugated secondary antibody was applied in blocking solution for $4 \mathrm{~h}$, followed by washes in PBS. The optic nerves were finally counterstained with DAPI, given final washes in $0.1 \%$ Triton $\mathrm{X}-100$, and mounted in Dako mounting medium. Images were acquired and processed as $Z$ 
A

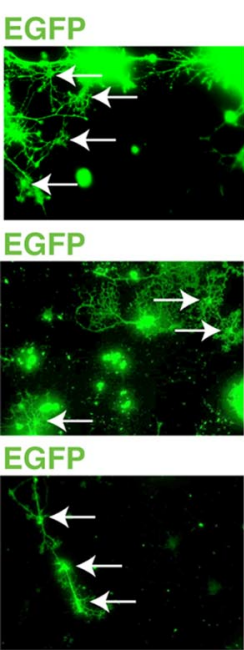

B
tdTomato

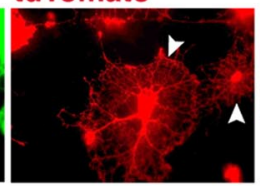

tdTomato

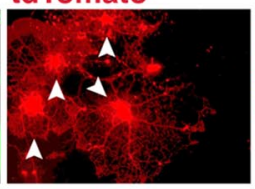

tdTomato

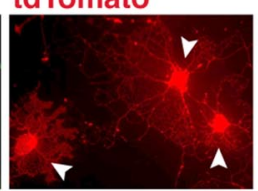

DIV3

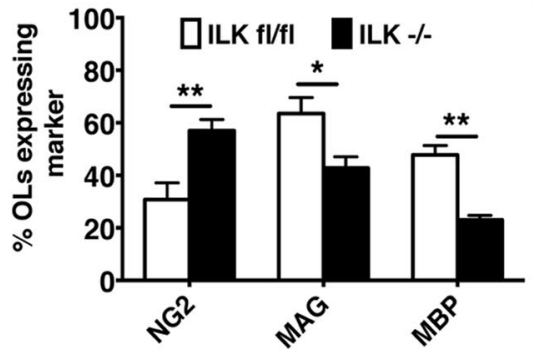

C

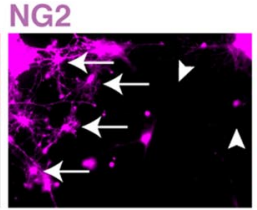

MAG

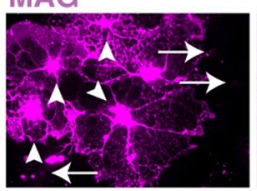

MBP

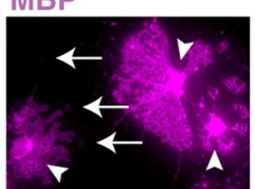

DIV6

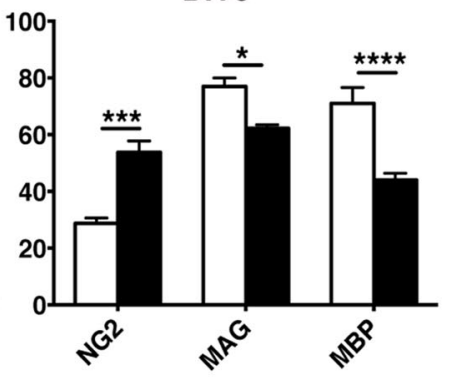

DIV6
DIV3

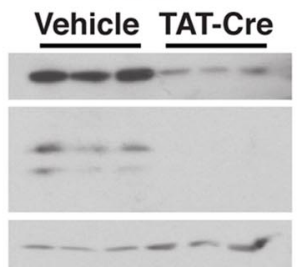

Vehicle TAT-Cre

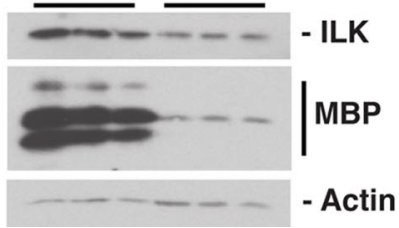

Figure 2. Loss of ILK impacts the expression of developmental stage-specific OL markers. $A$, Immunostaining of TAT-Cre treated DIV6 OL cultures for NG2, MAG, and MBP. Arrows and arrowheads indicate $I / k^{-/-}$and $I / K^{f / f / f l} 0 \mathrm{Ls}$, respectively. B, Quantification of percent of $/ / k^{-/-}$versus $/ k^{f / f f l}$ OLs expressing NG2, MAG, or MBP at DIV3 and DIV6. C, Western blots of TAT-Cre and vehicle lysates probed for ILK and MBP, with actin serving as a loading control. Data represent the mean $\pm \operatorname{SEM}(n=4) .{ }^{*} p<0.05$; ${ }^{* *} p<0.01$; ${ }^{* * *} p<0.001 ;{ }^{* * * *} p<0.0001$ (two-way ANOVA followed by Bonferonni post-tests). Scale bar, $100 \mu \mathrm{m}$.

stacks through the whole-mount preparation to visualize OLs and associated internodes in their entirety.

Electron microscopy. Mice were anesthetized with Avertin and perfused transcardially with Karnovsky's fixative (4\% PFA, 5\% glutaraldehyde, 0.08 m sodium cacodylate, $\mathrm{pH} 7.4$ ). The optic nerve was then removed and postfixed in Karnovsky's fixative at $4^{\circ} \mathrm{C}$. Fixed optic nerves were cut into ultrathin sections, stained with uranyl acetate and lead citrate, and analyzed by electron microscopy. Axon and myelin diameters were determined using the "analysis" tool in ImageJ set to a known scale. Number of myelinated fibers relative to total fibers was then determined and subdivided into groups by axon diameter. The $\mathrm{G}$ ratio was calculated by dividing the axon diameter by the axon plus myelin diameter.

Western blot. Mixed glial cultures were cooled on ice for $3 \mathrm{~min}$ and washed with ice-cold PBS. Cells were scraped off the dishes into protein lysis buffer (50 mm Tris- $\mathrm{HCl}, 150 \mathrm{~mm} \mathrm{NaCl}, 1 \% \mathrm{NP}-40$ ) containing protease inhibitor cocktail $(0.01 \mathrm{mg} / \mathrm{ml}$ pepstatin, $0.01 \mathrm{mg} / \mathrm{ml}$ aprotinin, $0.01 \mathrm{mg} / \mathrm{ml}$ leupeptin, $5 \mathrm{~mm} \mathrm{Na}_{3} \mathrm{VO}_{4}, 1 \mathrm{~mm}$ PMSF) and centrifuged at high speed to remove insoluble material. For optic nerves, protein was extracted through tissue homogenization in a lysis buffer solution (50 mм Tris pH 7.4, $150 \mathrm{~mm} \mathrm{NaCl}, 0.1 \%$ SDS, $0.5 \%$ sodium deoxycholate, and $1 \%$ Triton X-100) containing protease inhibitor cocktail plus 50 $\mathrm{mm} \mathrm{NaF}$. Optic nerves from three mice were pooled for each protein sample. For Western blotting of proteins obtained from OL cultures, vessels were briefly cooled on ice before cells were lysed in a commercial lysis buffer (Cytoskeleton). Lysate was then centrifuged at high speed to remove insoluble material. Western blot exposure films were scanned with EPSON Perfection 2450 PHOTO scanner, and images were imported into ImageJ. A box of standard dimensions was placed over each band of a given blot, and the mean gray value was measured for each band. Levels of a given protein of interest were normalized to the GAPDH band intensity.

His-TAT (trans-activator of transcription)NLS (nuclear localization sequence)-Cre (TATCre) treatment. TAT-Cre (Excellgen) was added to mixed glial cultures at a concentration of $\sim 2-5 \mu \mathrm{M}$ for $1-4 \mathrm{~h}$. The following day, the efficiency of the recombination was qualitatively assessed by EGFP fluorescence. OPCs were extracted from the mixed glial cultures and seeded onto Ln- 2 substrate $72 \mathrm{~h}$ after TATCre administration as described previously (O'Meara et al., 2011b).

Small G-protein ELISA (G-LISA) RhoA activation assay. DIV3 vehicle and TAT-Cretreated primary OLs were scraped into RhoA G-LISA lysis buffer, and clarified lysates were flash frozen in liquid nitrogen. The G-LISA assay was conducted on the lysates according to the manufacturer's instructions (Cytoskeleton). Raw luminescence values were normalized to total RhoA levels as measured by Western blotting.

Statistical analysis. All statistical analyses were performed using Prism 5/6 GraphPad software. Unless stated otherwise, two-tailed Student's $t$ tests were used for statistical analyses, with significance set at $p<0.05$.

\section{Results}

ILK is required for primary

\section{OL differentiation}

ILK is well known for its role in focal adhesion stabilization (Legate et al., 2006), a function highly dependent on its binding partner $\alpha$-parvin. Through $\alpha$-parvin, ILK is connected to the actin cytoskeleton, thus linking cellular interior and ECM. Both ILK and $\alpha$-parvin proteins were detected at all differentiation time points in cultured primary murine OLs (Fig. 1A). Expression of $2^{\prime}, 3^{\prime}$-cyclicnucleotide $3^{\prime}$-phosphodiesterase (CNP) and MBP indicates the degree of OL differentiation in the cultures, as these are intermediate and late markers of OL differentiation, respectively (Fig. $1 A)$. To investigate the role of ILK in primary OL differentiation, we used a conditional knock-out approach taking advantage of the $I l k^{f l / f l}$ mutant mouse (Terpstra et al., 2003) (Fig. 1B). To track which cells had undergone Cre-mediated recombination, Ilk ${ }^{f l f l}$ mice were crossed to the $m T / m G$ reporter line (Muzumdar et al., 2007). Recombination was achieved in culture through the use of TAT-Cre (Peitz et al., 2002), resulting in cessation of tdTomato expression and induction of EGFP (Fig. $1 B, C$ ) in conjunction with excision of the floxed region within the mouse Ilk gene (Fig. 
1D). Administration of TAT-Cre also significantly reduced ILK protein levels, and that of its obligate partner $\alpha$-parvin in transgenic mixed glial cultures (Fig. $1 E, F)$. OPCs were then derived from these TAT-Cre-treated mixed glial cultures as described previously (O’Meara et al., 2011b) and seeded on Ln-2 substrates as a purified population for further study.

OPC differentiation requires both molecular and morphological cellular alterations. Molecular differentiation coincides with decreased expression of NG2 concomitant with MAG and MBP expression. Upon loss of ILK $\left(I l k^{-/-}\right)$, a significant proportion of OPCs persisted as NG2 ${ }^{+ \text {ve }}$ precursors at DIV3 and DIV6 of the differentiation time course (Fig. 2A,B). Accordingly, fewer $I l k^{-/-}$OLs expressed MAG or MBP as compared to wild-type $\left(I l k^{f l / f l}\right)$ cells. However, a certain proportion of $\mathrm{Ilk}^{-1-}$ OLs expressed MAG at DIV3 and DIV6; thus, persistence of $\mathrm{NG} 2^{+ \text {ve }}$ precursors was not a completely penetrant phenotype in response to ILK loss. Furthermore, MBP protein levels (as measured by Western blot) were decreased in TAT-Cre-treated cultures at both DIV3 and 6 (Fig. 2C).

To investigate whether this apparent delay in lineage progression was an artifact of differential expansion/collapse of $I l k^{-1-}$ or $I l k^{f l f l}$ OL populations, we conducted a series of cell death and proliferation assays. When total numbers of $I l k^{-I-}$ and $I l k^{f l / f l}$ OL-lineage cells were respectively considered as $100 \%$ at DIV1, there was no subsequent difference in cell counts between the genotypes at either DIV3 or DIV6 (Fig. 3A). This suggests that loss of ILK does not translate to compromised survival of OL-lineage cells. In addition, there was no significant difference in the percentage of cleaved caspase $3^{\text {+ve }}$ OL-lineage cells at DIV1, DIV3, or DIV6 (Fig. $3 B$ ). When this same cleaved caspase 3 data was parsed to segregate mature and immature OL-lineage cells, we still did not observe any significant difference in cleaved caspase 3 activity between $I l k^{-/-}$and $I l k^{f l f l}$ populations (Fig. $3 C$ ). Finally, we investigated whether there were differences in the rate of proliferation between $I l k^{-/-}$and $I l k^{f l f l}$ OPCs. We did not observe any difference in BrdU incorporation after a $4 \mathrm{~h}$ pulse at DIV2 (Fig. $3 D$ ). Thus, our data strongly suggest a role for ILK in the initiation of a molecular differentiation program triggering MAG and MBP expression. Simply stated, upon loss of ILK, OPCs tend to persist as $\mathrm{NG} 2^{+\mathrm{ve}}$ precursors throughout the $6 \mathrm{~d}$ differentiation time course.

\section{Loss of ILK inhibits morphological maturation of OLs in primary culture}

OL morphological differentiation is characterized by extension of multiple processes by OPCs, eventually generating myelin-like membranous structures. This morphological maturation coincides with the expression of MAG. At DIV3 of differentiation, $\mathrm{MAG}^{+\mathrm{v} e}$ $I l k^{f l f l}$ OLs had developed a complex arbor network, and at DIV6, these OLs had further differentiated to form myelin-like membranes (Fig. 4A, top). Interestingly, most $\mathrm{MAG}^{+ \text {ve }} \mathrm{Ilk}^{-/-}$OLs did not produce either an arbor network or myelin-like membranes (Fig. $4 A$,
B
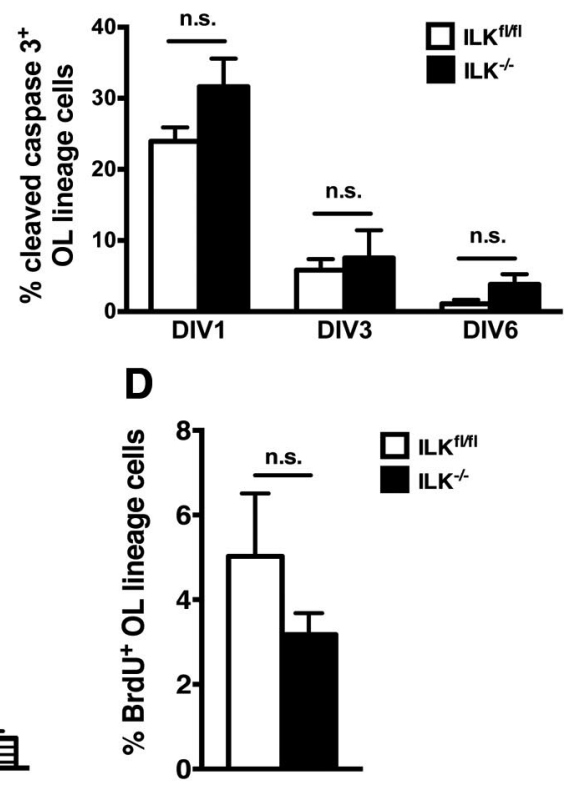

Figure 3. No significant difference in OL survival, cleaved caspase 3-mediated death, or proliferation upon ILK depletion. $\boldsymbol{A}$, considered as distinct populations. $\boldsymbol{D}$, Percentage of $\mathrm{BrdU}^{+}{ }^{+} \mathrm{ve} 0 \mathrm{Ls}$ after a $4 \mathrm{~h}$ pulse on DIV2. Data represent the mean $\pm \operatorname{SEM}(\boldsymbol{A}$, $n=4 ; \boldsymbol{B}-\boldsymbol{D}, n=3)$. n.S., No significant difference ( $\boldsymbol{A}-\boldsymbol{C}$, two-way ANOVA followed by Bonferonni post-tests; $\boldsymbol{D}$, Student's $\boldsymbol{t}$ test).

bottom). Rather, they only extended a few primary arbors. To quantify this observation, a staging scheme was developed, from Stage 1 to Stage 4, where cells were binned based on their increasing morphological complexity (Fig. 4B). At DIV3, $\mathrm{MAG}^{+\mathrm{ve}} \mathrm{Ilk}^{-/-}$OLs were predominantly Stage 1 , whereas $\mathrm{MAG}^{+\mathrm{ve}} I l k^{f l f l}$ OLs were largely Stage 3 (Fig. 4C). At DIV6, most $\mathrm{MAG}^{+\mathrm{ve}}$ Ilk $^{f l / f l}$ OLs were of Stage 4 morphology, but the majority of $\mathrm{MAG}^{+\mathrm{ve}} \mathrm{Ilk}^{-/-}$OLs persisted as Stage 1 (Fig. $4 C$ ). A subset of $I l k^{-/-}$OLs attained Stage 4 morphology at DIV6; however, their cellular area was significantly reduced as compared to Stage $4 \mathrm{MAG}^{+\mathrm{ve}} I l k^{f l / f l}$ OLs (Fig. $4 D, E$ ). The observed morphological deficits resulting from ILK loss were not a consequence of EGFP induction, as Cre-recombined $I l k^{+/+} ; m T / m G$ OLs displayed normal morphology (data not shown).

Loss of ILK impacts in vitro myelinating capacity of OLs Due to the morphological deficits observed when $\mathrm{Ilk}^{-/-}$OLs are cultured on Ln-2, we hypothesized that this would translate to compromised myelinating capacity in an in vitro myelination paradigm. To this end, we used DRGNs in coculture with primary OLs as described previously (O'Meara et al., 2011b). At DIV3 of coculture, there was no significant difference in the capacity for $I l k^{-/-}$OLs to contact and enwrap DRGN neurites compared to $I l k^{f l f l}$ OLs (Fig. 5A-C). However, at DIV6, Ilk ${ }^{-/-}$ OLs contacted fewer DRGN neurites and had a reduced capacity to enwrap neighboring neurites with $\mathrm{MBP}^{+ \text {ve }}$ membrane (Fig. $5 A-C)$. The driving force underlying these deficits appeared to be an impaired ability of $I l k^{-/-}$OLs to form myelin leaflets (Fig. $5 D)$. These structures were observed solely when OLs were cocultured with neurons, and may represent an in vitro version of early myelin sheaths. Ilk ${ }^{-/-}$OLs produced significantly fewer myelin leaflets per cell than $I l k^{f l f l}$ OLs (Fig. $5 E$ ). These defects were not a result of ectopic EGFP expression, as $I l k^{+/+} ; m T / m G$ OLs myelinated DRGN neurites normally, and produced expected numbers 
A

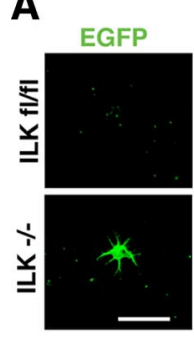

B
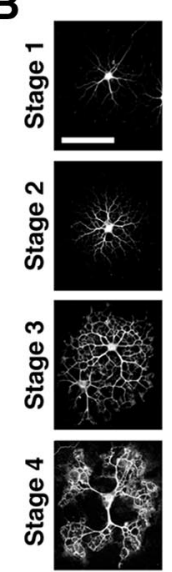

D
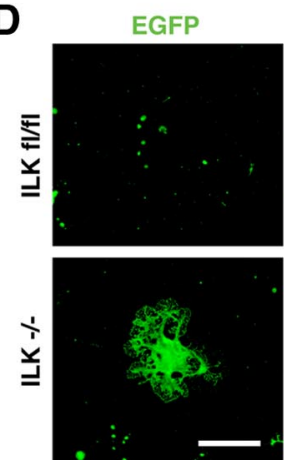

C
DIV3
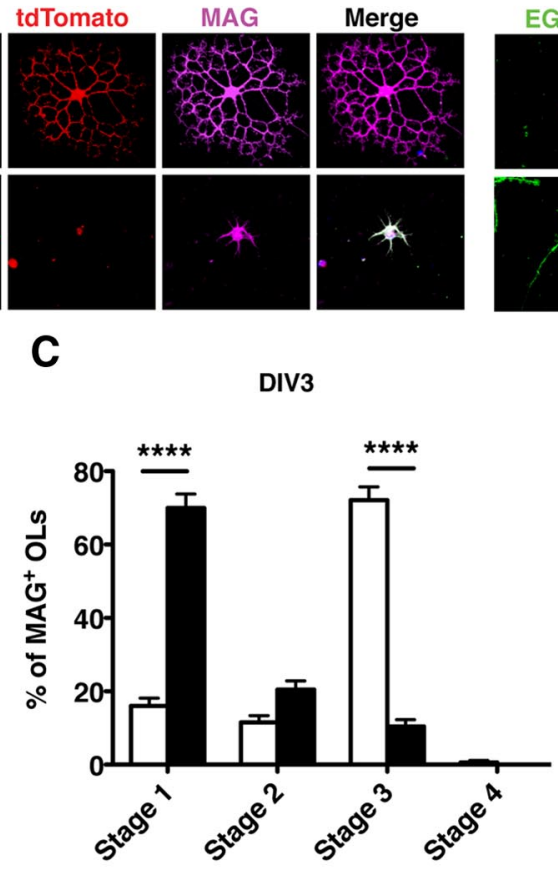

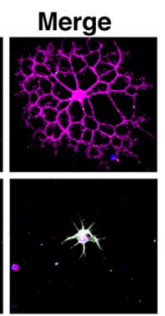

DIV3

DIV6
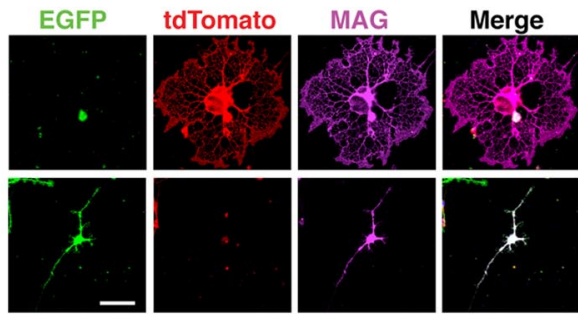

DIV6
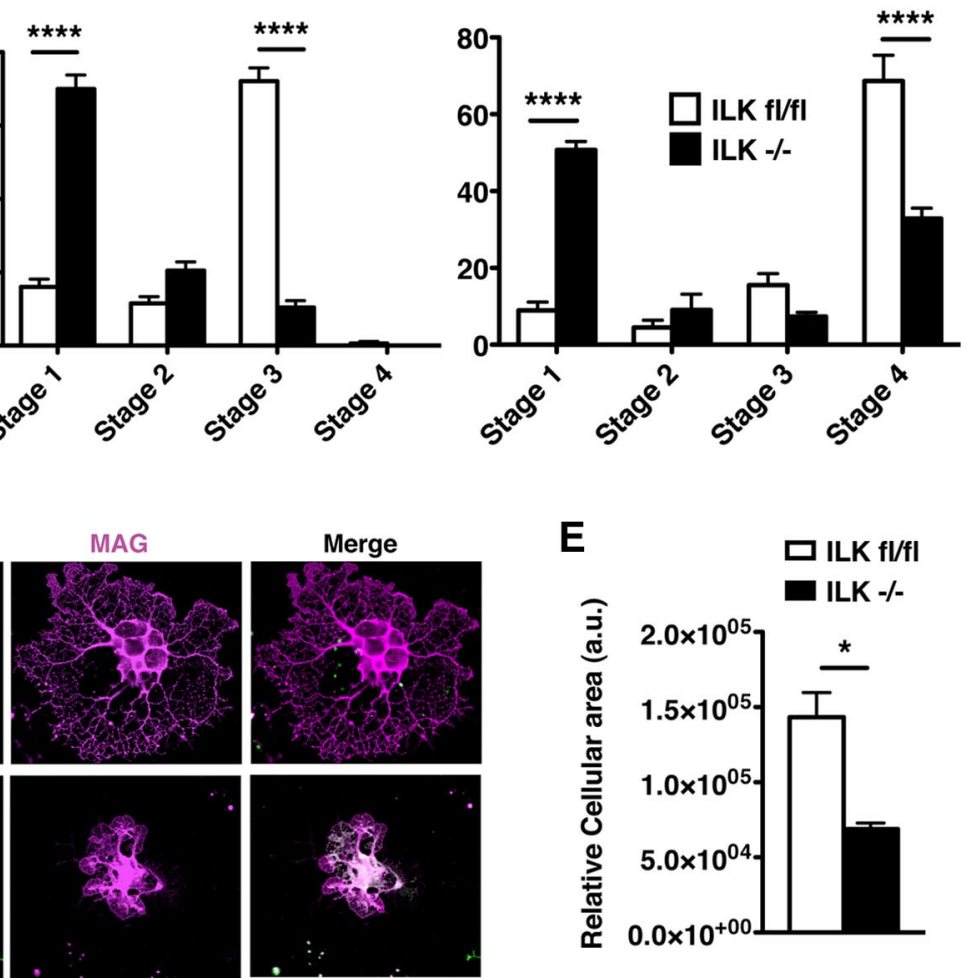

Figure 4. Loss of ILK perturbs morphological maturation of OLs. A, Immunofluorescence micrographs depicting morphology of MAG ${ }^{+v e} / / k^{-/-}$and $/ / K^{f / / f l}$ at DIV3 and DIV6. B, Staging scheme used to categorize the morphological complexity of MAG ${ }^{+v e} 0 \mathrm{Ls}$. C, Quantification of percent of $/ / \mathrm{k}^{-/-}$and $/ / \mathrm{K}^{\mathrm{Al} / \mathrm{I}} \mathrm{MAG}^{+ \text {ve }} 0 \mathrm{Ls}$ that fall into each of the four morphological stages at DIV 3 and

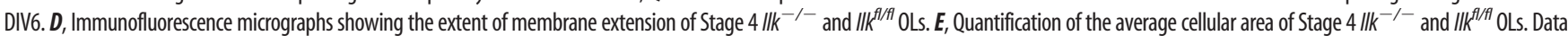
represent the mean \pm SEM $(n=4) .{ }^{*} p<0.05$; ${ }^{* * *} p<0.0001$ (E, Student's t test; $\boldsymbol{C}$, two-way ANOVA followed by Bonferonni post-tests). Scale bars: $50 \mu \mathrm{m}$.

of myelin leaflets (data not shown). In addition, we confirmed that there were no differences in the density of DRGN neurite bed underlying myelinating OLs (data not shown), suggesting the OLs themselves were solely responsible for the myelination phenotypes in response to ILK loss.

\section{Generation of ILK conditional knock-out mice for} in vivo study

To study the role of ILK in CNS myelination in vivo and avoid embryonic lethality associated with ILK deletion, we used the Cre-loxP system. Ilk ${ }^{f l f l}$ mice were crossed to $P l p-C r e E R^{T}$ mice to generate $I l k^{f l f l} ; P l p-C r e E R^{T}$ conditional knock-out mice (hereafter referred to as $I l k c K O$ mice). The $P l p$-CreER ${ }^{T}$ line of mice allows for spatial and temporal control of floxed Ilk recombination; the Cre gene is placed under the control of the proteolipid protein $(P l p)$ promoter, allowing for OL-specific expression (Doerflinger et al., 2003). As well, the Cre protein is fused to a mutated estrogen receptor, requiring tamoxifen administration for nuclear translocation (Fig. 6A).
The optic nerve was chosen as a model system to study the impact of $I l k$ gene deletion on myelination, as it offers a relatively homogeneous population of cell types, with a large percentage of OLs, compared to other CNS tissues. Since myelination of the optic nerve is initiated $\sim 6 \mathrm{~d}$ postnatally (Thomson et al., 2005), Ilk cKO mice and WT littermates were administered tamoxifen at $\mathrm{P} 4$. Western blot analysis revealed a decrease in total ILK protein levels in the optic nerves of these mice following tamoxifen injection (Fig. 6B). To verify specificity of the promoter to the OL lineage, $I l k c K O$ mice were crossed to the $m T / m G$ reporter line (generating Ilk $c K O ; m T / m G$ mice). In these mice, EGFP is expressed predominantly in cells positive for the myelin markers MBP and MAG (Fig. 6C), demonstrating the specificity of the Plp promoter to OLs.

Transient amyelination following ILK ablation in vivo Initial analysis of IIk $c K O$ mice revealed no overt signs of shaking, ataxia, tremor, or head wobbling following tamoxifen injection at P4. Mice were killed at two developmental time points, P14 and 
A
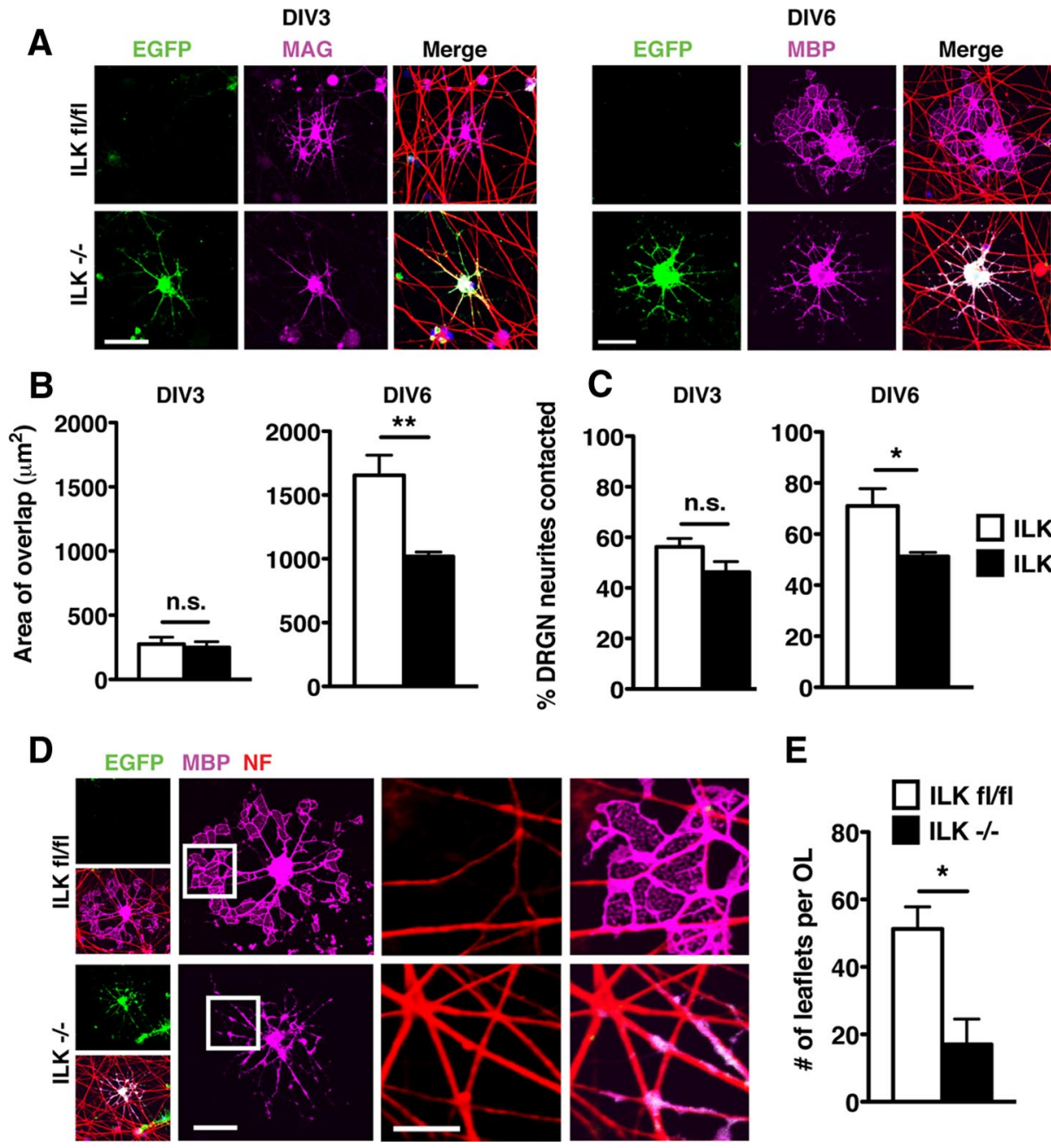

Figure 5. Loss of ILK disrupts ability of OLs to myelinate axons in vitro. A, Immunofluorescence micrographs of $/ / k^{-/-}$and $/ I K^{f l / f I}$ OLs myelinating DRGN neurites at DIV3 and DIV6 of coculture. B, Quantification of the area of overlap of myelin membrane with DRGN neurites by $/ / k^{-/-}$and I/k ${ }^{f / f l}$ OLs at DIV3 and DIV6. C, Quantification of the percentage of neighboring DRGN neurites contacted by $I / k^{-/-}$and $I / k^{f / / f l}$ OLs. D, Immunofluorescence micrographs depicting the structure of membrane extensions/leaflets for $I / k^{-/-}$and $/ / k^{f / / f l} 0 \mathrm{Ls}$. E, Quantification of the number of membrane extensions produced per cell for $I / k^{-/-}$and $I / k^{f l / f l}$ OLs. Data represent the mean \pm SEM $(n=4) .{ }^{*} p<0.05$; ${ }^{* *} p<0.01$ (Student's $t$ test). Scale bar: $50 \mu \mathrm{m}$.

P28, for ultrastructural analysis by electron microscopy. The optic nerves of P14 Ilk cKO mice displayed a significant reduction in total number of myelinated small caliber axons $(0.3-0.8 \mu \mathrm{m})$ relative to WT littermate controls (Fig. $6 D, E$ ). In contrast, there was no significant difference in number of myelinated large caliber axons ( $0.8 \mu \mathrm{m}$ and above) at this time point (Fig. $6 D, E)$. That small rather than large caliber axons are affected is in concordance with previous work done on OL-specific knock-out mice for other members of the integrin-signaling pathway (Chun et al., 2003; Câmara et al., 2009; Forrest et al., 2009). To determine whether myelin thickness was also affected by ILK loss, we assessed the G-ratio (axon diameter/axon and myelin diameter) of axons in two separate groups; those $<0.8 \mu \mathrm{m}$ and those $\geq 0.8 \mu \mathrm{m}$ in diameter (Fig. $6 F$ ). There was no significant difference in the average G-ratio of axons either $<0.8 \mu \mathrm{m}$ or $\geq 0.8 \mu \mathrm{m}$. As well, no difference was observed in axonal distribution (by diameter) between WT and Ilk cKO littermates (Fig. 6G), excluding a shift in axon caliber frequency as responsible for the observed decrease in total number of myelinated small caliber axons.

Interestingly, when Ilk cKO mice were analyzed at P28, there was no observable difference in total number of myelinated fibers (at any given diameter) relative to control mice (Fig. $6 H, I$ ). In ad- dition, there was no significant difference in the average G-ratio of axons with diameters either $<0.8 \mu \mathrm{m}$ or $\geq 0.8 \mu \mathrm{m}$ in P28 optic nerves (Fig. $6 J$ ). Furthermore, no significant shift was observed between control and Ilk cKO mice in axonal distribution by diameter (Fig. $6 \mathrm{~K}$ ), discounting the possibility of axonal loss as explanation for the resurgence of small myelinated fibers by P28. Rather, our results imply gradual myelination recovery of P14 amyelinated axonal populations in the ILK-depleted optic nerve.

The transient defects observed are due neither to a loss or a gain in total number of OLs as measured by NG2 ${ }^{\text {ve }}$ OPCs and $\mathrm{CC} 1^{+ \text {ve }}$ mature OLs at P14 or P28 (Fig. $7 A, B$ ). To assess the possibility of OL turnover, we measured the number of cleaved caspase $3^{+\mathrm{ve}}$ cells in the optic nerves of P14 Ilk cKO and WT mice. No significant increase in the number of apoptotic cells was observed in ILK-depleted optic nerves (Fig. 7C). Furthermore, qualitative analysis for the abundance of recombined $\left(\mathrm{EGFP}^{+\mathrm{ve}}\right.$ ) $I l k^{-/-}$OLs in the optic nerves of Ilk cKO;mT/mG mice demonstrated a persistent $\mathrm{EGFP}^{+ \text {ve }}$ cell population capable of forming $\mathrm{MBP}^{+\mathrm{ve}}$ myelin tracts across multiple time points (data not shown). If $I l k^{-/-}$OLs were indeed being turned over, we would expect a progressive loss in EGFP signal as $I l k^{-/-}$cells were replaced by WT precursors. 
A

Inducible Cre Ilk floxed allele HPLP Creent t

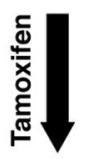

B

Optic Nerve

ILK fl/fI ILK cKO

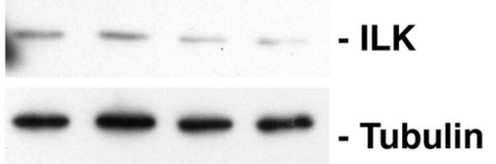

H PLP CreERt H

C P8 Optic Nerve
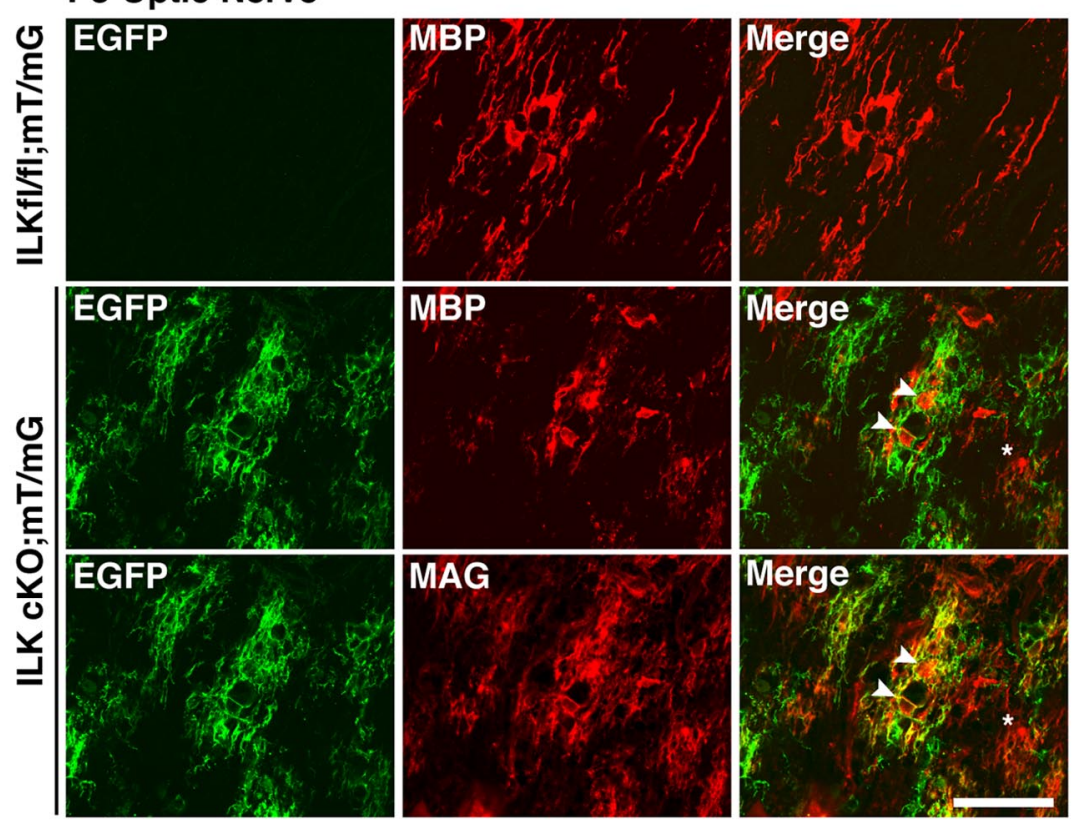

F
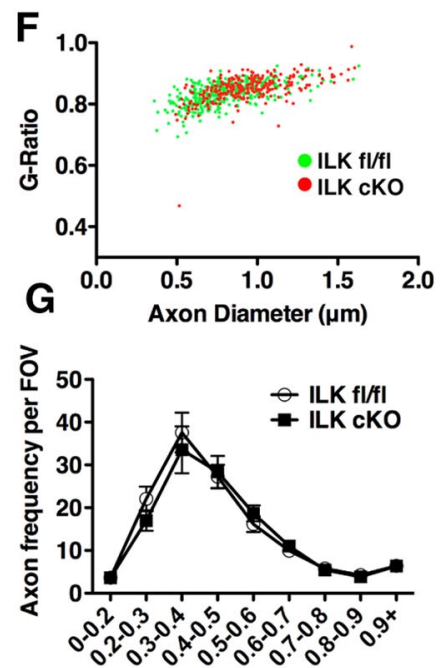

Axon Diameter $(\mu \mathrm{m})$
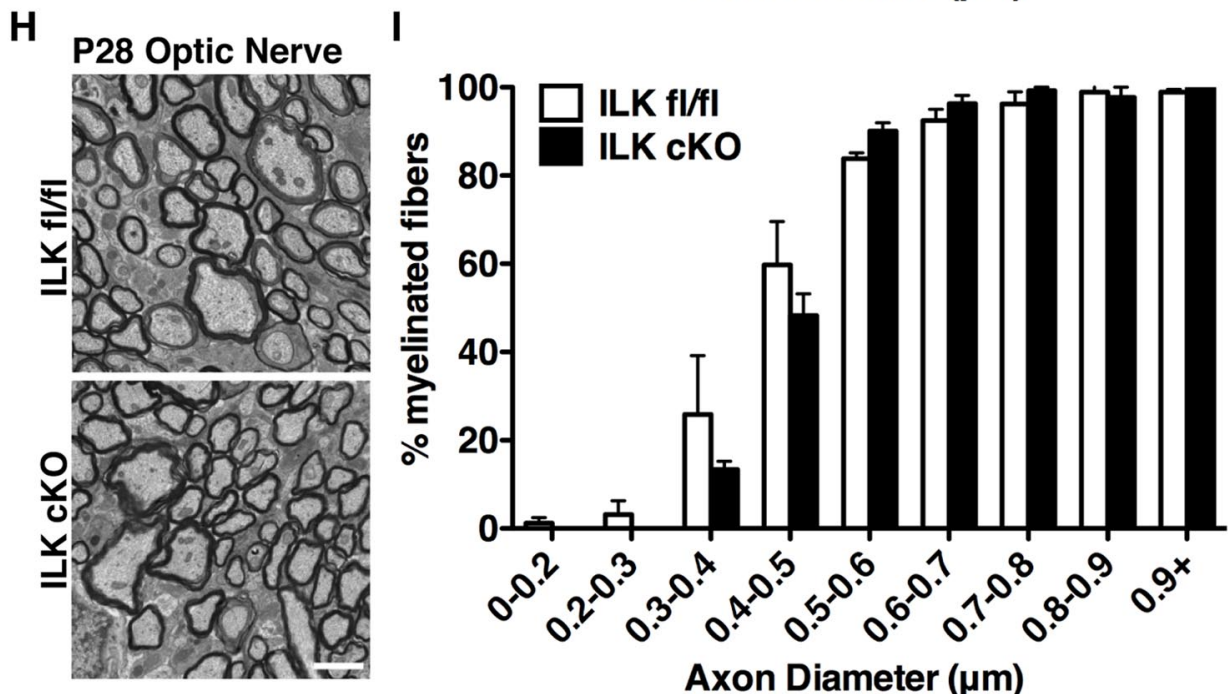
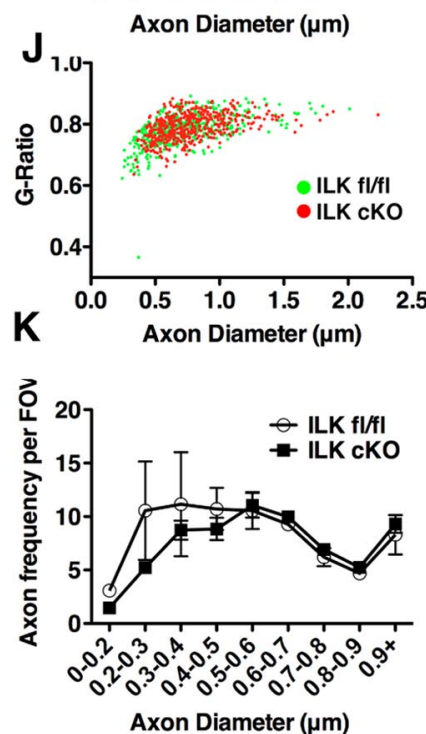

Figure 6. Number of myelinated axons is decreased in the optic nerves of tamoxifen treated Ilk $c K 0$ mice at P14 but not at P28. $A$, Ilk $c K 0$ mice were generated by crossing Plp-CreER ${ }^{T}$ transgenic mice with $/ / k^{f l / f l}$ mice. Tamoxifen was administered to induce (re translocation into the nucleus whereupon the Ilk gene was excised. $\boldsymbol{B}$, Western blot analysis demonstrates (Figure legend continues.) 
In an effort to draw parallels between defects observed in vitro (morphological aberrations) and in vivo (loss of myelination), we used a low-dose tamoxifen regimen in our Ilk cKO;mT/mG and PLPCreER ${ }^{T} ; m T / m G$ reporter control animals. Reducing tamoxifen levels allowed for spatial resolution of individual recombined OLs and associated myelin processes. Following administration of the drug, mice were killed at P14, and the optic nerves were removed for whole-mount preparations. A series of $Z$ stack images were taken to capture recombined OLs in their entirety. Strikingly, at a strictly qualitative level, many of the ILK-depleted OLs displayed fully formed myelin internodes similar to controls (Fig. 8A). However, the average internode length was less than that measured for reporter controls (Fig. $8 A, B$ ), corroborating our in vitro data for a subset of mature ILK-depleted OLs, which form smaller amounts of membrane. As well, loss in internode length implies a defect in the growth of the process responsible, as the distance it is able to travel around the axon will determine length of the myelin segment. In conjunction, we measured internode diameter to account for possible bias as a result of axon diameter (larger axons having longer myelin internodes and vice versa). No significant difference was observed between ILK-depleted and control OLs (Fig. $8 B$ ) eliminating the variable as potential confounder. We did, however, observe ILK-depleted OLs whose processes failed to form myelin internodes (Fig. 8C). While occasionally present in controls, the defect was more prevalent in the optic nerves of Ilk $c K O ; m T / m G$ mice, suggesting a role for ILK in directing myelin formation following axonal contact and/or process extension in vivo, defects observed in both purified and cocultured OLs in vitro. Together, our data, both in vitro and in vivo, point to a role for ILK in the initial steps of myelination and suggest that the observed amyelination is not due
A

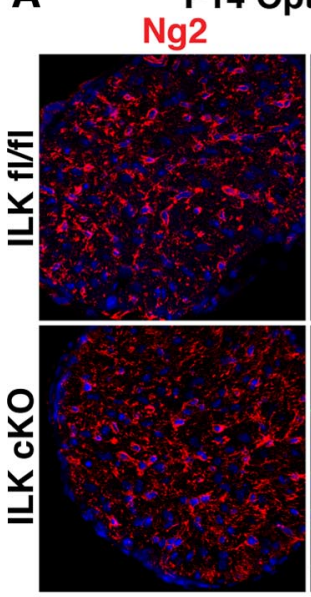

B

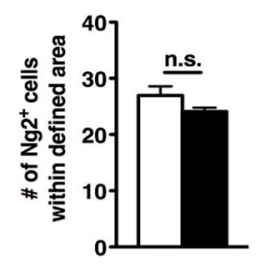

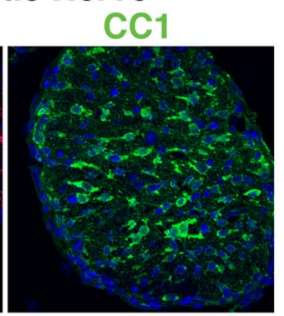
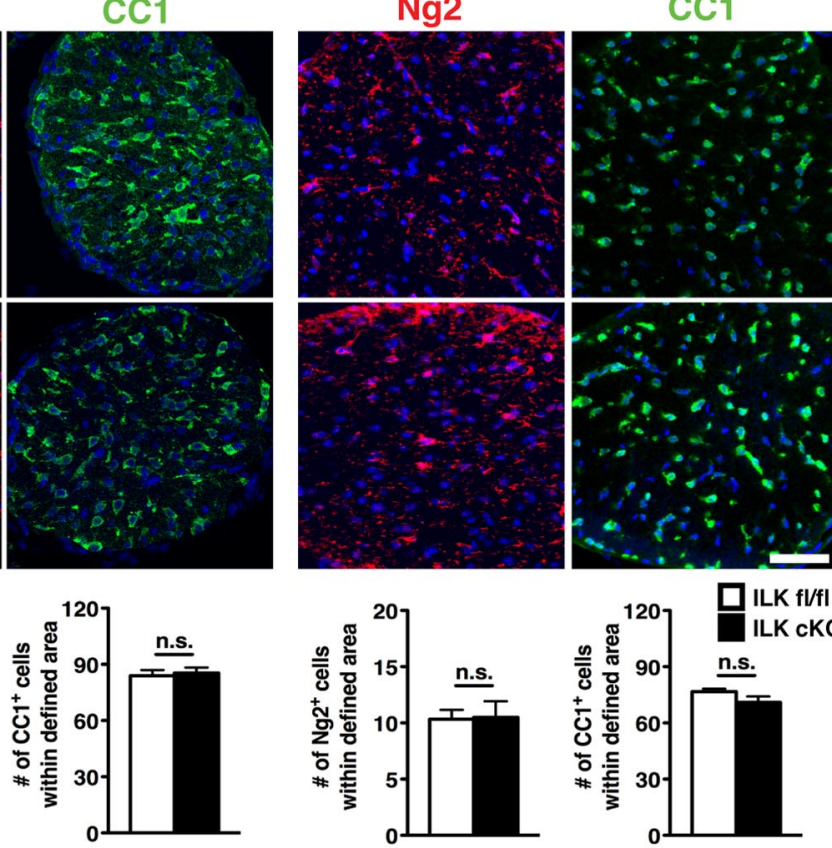

C

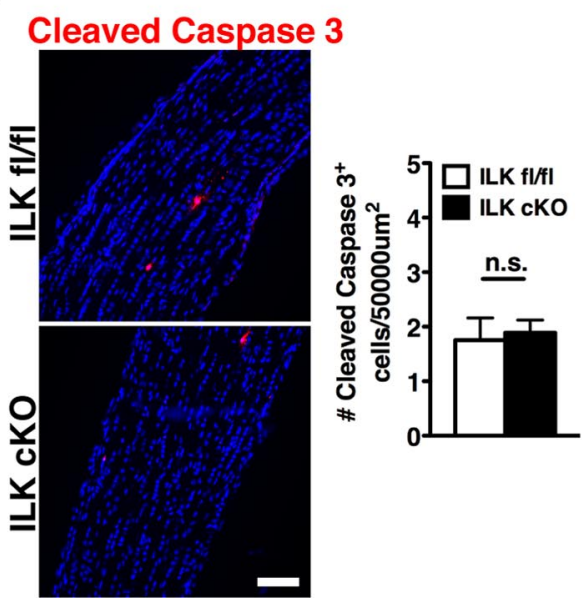

Figure 7. Number of precursor and mature $\mathrm{OL} s$ is unchanged in optic nerves of $/ / \mathrm{k}$ C $K O$ mice. $A$, Immunofluorescence micrographs of $\mathrm{NG2}{ }^{+\mathrm{ve}} \mathrm{OPCs}(\mathrm{red})$ and $\mathrm{CC}^{+}{ }^{+\mathrm{ve}}$ mature $\mathrm{OLs}$ (green) counterstained with DAPl in the optic nerves of $/ / \mathrm{k}$ CKO and WT mice at P14 or P28. $\boldsymbol{B}$, Quantification of NG2 ${ }^{+v e} \mathrm{OPCS}$ and $\mathrm{CC} 1^{+ \text {ve }}$ mature $0 \mathrm{Ls}$ at P14 and P28. Respective cells were counted within a defined area of the optic nerve. $C$, Immunofluorescence micrographs of cleaved-caspase $3^{+v e}$ cells counterstained with DAPI along the length of an optic nerve in P14 /lk cKO and WT mice. Quantification for total number of cleaved-caspase $3^{+ \text {ve }}$ cells within $50000 \mu \mathrm{m}^{2}$ of the P14 optic nerve. Data represent the mean $\pm \operatorname{SEM}(n=3)$. n.s., No significant difference (Student's $t$ test). Scale bars: $50 \mu \mathrm{m}$.

to a loss of OLs but rather to a defect in OL branching and membrane formation.

(Figure legend continued.) reduction of ILK protein in the optic nerves of P4 tamoxifen injected Ilk cKO mice in comparison to WT controls. C, Optic nerves from control II/ $k^{f / f f} ; \mathrm{mT} / \mathrm{mG}$ littermates at P8 contain MBP ${ }^{+v e}$ OLs but no EGFP signal. Optic nerves from P4 tamoxifen injected Ilk cK0;mT/mG mice killed at P8 show colocalization of MBP/MAG ${ }^{+ \text {ve }} 0 \mathrm{~L}$ cell bodies (both stains are on the same optic nerve section) with EGFP (arrowheads). There are also MBP/ $\mathrm{MAG}^{+\mathrm{ve}}$ cell bodies that do not express EGFP (asterisks). $\boldsymbol{D}, \boldsymbol{H}$, Electron micrographs of optic nerves from P14 and P28 Ilk cKO and control mice given tamoxifen at P4. E, I, Quantification for percentage myelinated axons at P14 and P28, further subdivided by axon caliber. $\boldsymbol{F}, \boldsymbol{J}$, Representative scatter plot of $\mathrm{G}$-ratio versus axon diameter at P14 and P28. $\mathbf{G}, \boldsymbol{K}$, Frequency histogram for axons of varying diameter per field of view (FOV) (3000 $\times$ magnification) at P14 and P28. Data represent the mean \pm SEM $(n=3-4) .{ }^{*} p<0.05 ;{ }^{* *} p<0.01(\boldsymbol{E}, \boldsymbol{I}$, Student's test; $\boldsymbol{G}, \boldsymbol{K}$, two-way ANOVA with Bonferroni post-tests). Scale bars: $\boldsymbol{C}, 50 \mu \mathrm{m} ; \boldsymbol{D}, \boldsymbol{H}, 1.5 \mu \mathrm{m}$.

Morphological deficits of $I l k$-deficient OLs are associated with abnormal actin accumulation and are partially rescued through Rho kinase inhibition

In our search for a mechanistic explanation for the aforementioned OL defects, we first explored the phosphorylation state of ILK's canonical downstream effectors Akt and GSK3 $\beta$. To our surprise, no apparent change in Akt (Ser 473) or GSK3 $\beta$ (Ser 9) phosphorylation was observed in ILK-depleted OL cultures at DIV3 or DIV6 (Fig. 9A,B). We thus sought to investigate other possible mechanisms that could account for the observed morphological aberrations. ILK has previously been shown to colo- 
A P14 Optic Nerve

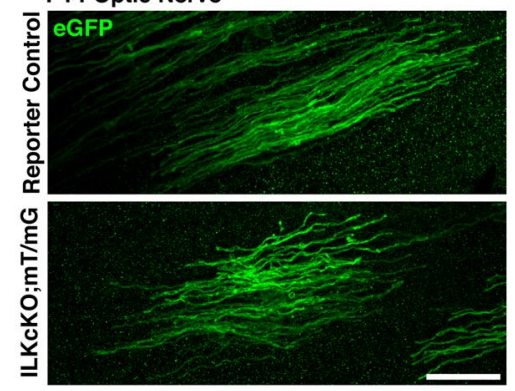

C P14 Optic Nerve

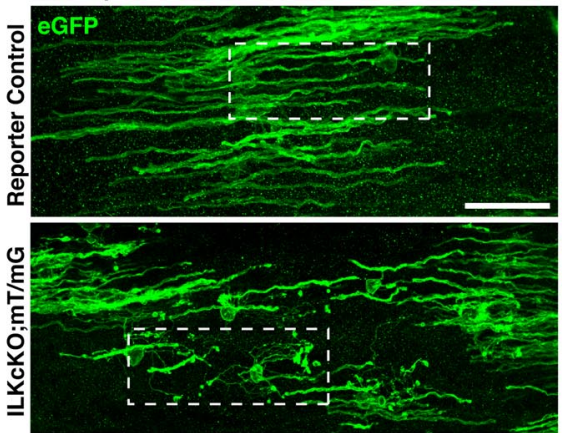

B
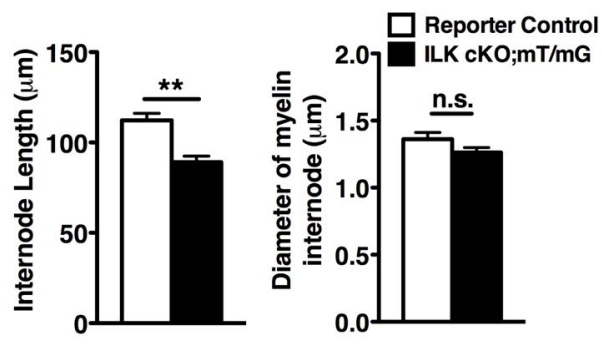

Zoom

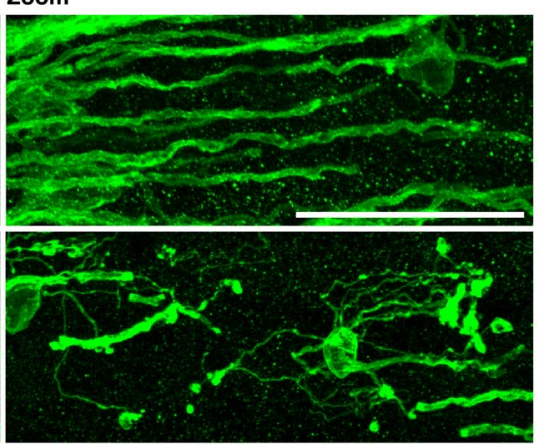

Figure 8. ILK regulates internode length and triggers internode formation in vivo. $A$, Compressed stack of immunofluorescence micrographs from the optic nerves of P14 PLPCreER ${ }^{T} ; m T / m G$ control and ILK $c K 0 ; m T / m G$ mice. EGFP (green) denotes a recombination event and allows for tracing of reporter only (top) or ILK-depleted internodes (bottom). B, Quantification of internode length and diameter between control and ILK-depleted mice. C, Compressed stack of immunofluorescence micrographs from the optic nerves of P14 PLPCreER $R^{T} ; m T / m G$ control and ILK CKO;mT/mG mice depicting abnormal morphology observed in a subset of ILKdepleted OLs. Data represents the mean $\pm \operatorname{SEM}(n=4)$. n.S., No significant difference. ${ }^{* *} p<0.01$ (Student's $t$ test). Scale bars: $50 \mu \mathrm{m}$.

calize with $\beta 1$ integrin and paxillin in OL focal adhesions (Chun et al., 2003). We further demonstrate ILK localization to the filamentous-actin (F-actin)-rich leading edge or distal tips of outgrowing processes in the immortalized OL cell line OLi-neu (data not shown). When ILK is lost from primary OLs, there is an abnormal accumulation of F-actin in the cell body and subcortically in the developing process (Fig. $9 C, D$ ). A well-known regulator of neural cell actin organization is the small RhoGTPase RhoA (Govek et al., 2005), and perturbation of RhoA results in morphologically aberrant OLs (Rajasekharan et al., 2009, 2010). As ILK is required for RhoA-dependent actin cytoskeleton reorganization (Graness et al., 2006), we hypothesized that the morphological deficits and actin accumulation in $\mathrm{Ilk}^{-1-}$ OLs is caused by upregulation of the RhoA signaling pathway. Indeed, when we probed for active RhoA levels, an increase in GTP bound RhoA was detected in our TAT-Cretreated DIV3 OL cultures (Fig. 9E).

Stimulation of the RhoA pathway involves activation of ROCK, an event that is associated with destabilization of actin. The ROCK inhibitor Y-27632 is often used to rectify the effects of overactive RhoA signaling. We tested whether Y-27632 treatment would improve the morphological deficits of $I l k^{-/-}$OLs. Interestingly, this did not rescue the morphological deficits of $\mathrm{MAG}^{+\mathrm{ve}} \mathrm{Ilk}^{-/-}$OLs (data not shown). Rather, Y-27632 had a specific impact on the morphology of immature $\left(\mathrm{MAG}^{-\mathrm{ve}}\right)$ $I l k^{-/-}$OLs (Fig. 10A). Under normal conditions, $\mathrm{MAG}^{-\mathrm{ve}}$ $I l k^{-/-}$OLs mostly displayed primary $\left(1^{\circ}\right)$ branched morphology, whereas $\mathrm{MAG}^{-\mathrm{ve}} I l k^{f l f l}$ OLs tended to have equal numbers of $1^{\circ}$ and secondary/tertiary $\left(2^{\circ} / 3^{\circ}\right)$ branched cells (Fig. 10B). Upon administration of Y-27632, quantification revealed a restoration of the proportion of $2^{\circ} / 3^{\circ}$ branched $\mathrm{MAG}^{-\mathrm{ve}} \mathrm{Ilk}^{-/-}$OLs to wild-type levels at DIV6 of culture (Fig. $10 B)$. It was unlikely that this phenomenon was a nonspecific event independent of ILK loss, since application of Y-27632 to $I l k^{f l f l}$ OLs did not enhance $\mathrm{MAG}^{-\mathrm{ve}} \mathrm{OL}$ morphology compared to $I l k^{f l / f l}$ vehicletreated cells.

We were apparently enhancing the morphology of an immature (i.e., $\mathrm{MAG}^{-\mathrm{ve}}$ ) population of $\mathrm{Ilk}^{-/-} \mathrm{OL}-$ lineage cells by inhibiting ROCK. We next sought to investigate whether these morphologically rescued $\mathrm{MAG}^{-\mathrm{ve}}$ cells were in fact $\mathrm{NG} 2^{+ \text {ve }}$ OPCs. To this end, we characterized the morphology of DIV6 $\mathrm{NG} 2^{+\mathrm{ve}} I l k^{-/-}$and $I l k^{f l f l}$ cells treated with either Y-27632 or vehicle. $\mathrm{Ilk}^{-1-} \mathrm{NG2}{ }^{+\mathrm{ve}}$ OPCs responded in a similar fashion as did the $\mathrm{MAG}^{-\mathrm{ve}}$ OLs described above (Fig. 10C). Y-27632 administration resulted in an increase from mainly $\mathrm{NG} 2^{+\mathrm{ve}}$ $1^{\circ}$ branched OPCs to predominantly $2^{\circ} / 3^{\circ}$ branched cells (Fig. 10D). Interestingly, in contrast to the above-described $\mathrm{MAG}^{-\mathrm{ve}}$ population, Y-27632 also enhanced the morphology of the $\mathrm{NG}^{+}{ }^{+\mathrm{ve}} I l k^{f l f l}$ population. However, even when considering this apparent indirect (i.e., ILK independent) impact of Y-27632 on NG2 ${ }^{\text {+ve }}$ OPC morphology, ROCK inhibition enhanced the morphology of $\mathrm{Ilk}^{-/-} \mathrm{NG} 2^{+\mathrm{ve}} \mathrm{OPCs}$ to a greater extent than $I l k^{f l f l}$ OPCs (Fig. $10 E)$. Thus, RhoA regulation seems to be ILK-dependent during distinct phases of OL development. Specifically, ILK appears to depend on RhoA signaling at the point of differentiation when OPCs are transitioning from NG2 ${ }^{+ \text {ve }}$ precursors to $\mathrm{MAG}^{-\mathrm{ve}}$ immature OLs.

\section{Discussion}

\section{ILK regulates OL development}

Following ILK loss in enriched primary OL cultures, two phenotypes were observed: (1) the persistence of $\mathrm{NG}^{+\mathrm{ve}}$ OPCs coupled with a decrease in mature $\left(\mathrm{MAG}^{+\mathrm{ve}}\right)$ cells, and (2) an inability of the $\mathrm{MAG}^{+\mathrm{ve}}$ population to form arborizations or myelin-like membranes (Fig. 11). At first glance, it is plausible to suspect a general delay in Ln-2 mediated differentiation as cause. While, to a degree, we believe this is true, several observations suggest this interpretation as overly simplistic. First, the persistence of $\mathrm{NG}^{+\mathrm{ve}}$ precursors in the $I l k^{-/-}$population remains static from DIV3 to DIV6, implying that this OL subpopulation requires ILK signaling for both morphological and molecular differentiation. Second, there is the discord between morphology and maturation markers observed in a separate OL subpopulation, those capable of MAG expression upon ILK loss. Together, this suggests a functional OL heterogeneity exists with regard to ILK. Some cells necessitate ILK to initiate the entire differentiation gamut, whereas others require ILK for morphological maturation only. Alternatively, ILK's role could be linked to the exact maturation stage of the precursor cell at the time of its deletion. In either case, we would assume functional differences are an outcome of signaling alteration downstream of ILK, most likely through a shift in ILK complex composition at the $\beta 1$ integrin cytoplasmic tail. Elucidation of the mechanistic switch that de- 
fines the observed OL subgroups will be important as we move toward a fuller understanding of OL development.

Initial characterization of P14 Ilk cKO optic nerves revealed a decrease in total number of myelinated small caliber axons. Extrapolating from our in vitro (aberrant morphological differentiation) and in vivo (low-dose tamoxifen) data, we suggest a dual explanation for the small axon phenotype, that $I l k^{-/-}$OLs suffer both from an inability to generate and extend the requisite network of processes as well as a deficiency in their capacity to initiate myelination following axonal contact. With regard to the former, OL morphological complexity is negatively correlated with the diameter of the axon(s) it myelinates. Individual OLs will either myelinate a large number of small axons or a small number of large axons (Butt and Berry, 2000; Almeida et al., 2011). Thus, following ILK loss, we would expect exacerbation of small axon amyelination as a result of the OL's inability to generate a high number of processes. The second mechanism, failure to initiate myelination following axonal contact, was first proposed by Câmara et al. (2009) in a dominant-negative model of $\beta 1$ integrin. The idea is as follows: once axonal contact is established, the OL process requires an axonal ligand "threshold" be broken to trigger a myelinating event. Larger axons are unaffected in this paradigm, as they provide excess surface ligand. Smaller axons, however, necessitate integrinmediated signal amplification and, as such, are preferentially affected.

In contrast to our own model, Câmara et al. (2009) initially proposed and then rejected the possibility of morphological abnormalities as a cause for small axon amyelination. We believe our in vitro data, together with the low-dose tamoxifen experiments, imply morphological defects following ILK loss in vivo. However, our two models do not preclude one from the other. Rather, they highlight possible differences in functional outcome between receptor and effector disruption. Our findings are also congruent with work published by others (Benninger et al., 2006), which controversially concluded no essential role for $\beta 1$ integrin in CNS myelination. Here, the authors focused primarily on $G$ ratio as a readout for myelination, which, similar to our own model, was unaffected. As well, the study was conducted primarily in older mice ( 2 months and older), by which time full phenotypic recovery had occurred in our model. Coupled with our work, these findings strongly suggest that the $\beta 1$ integrin signaling pathway is critical for myelination during a small developmental window, with compensation occurring thereafter.

As alluded to, our in vivo model demonstrates the capacity for compensation. When considering the transient nature of the

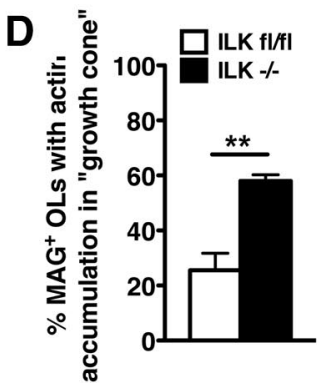
Scale bars: $50 \mu \mathrm{m}$.
B
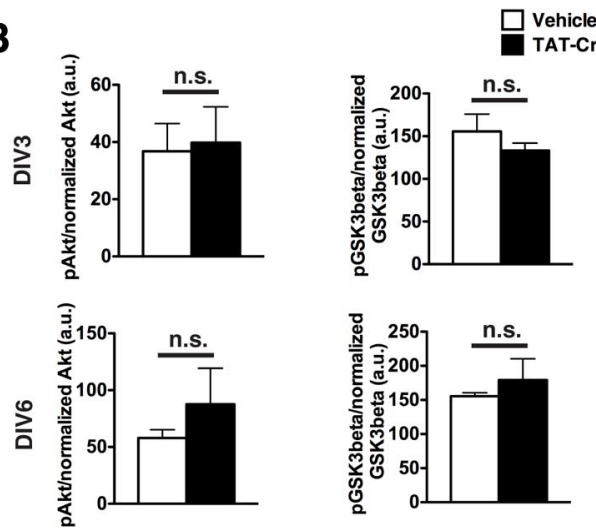
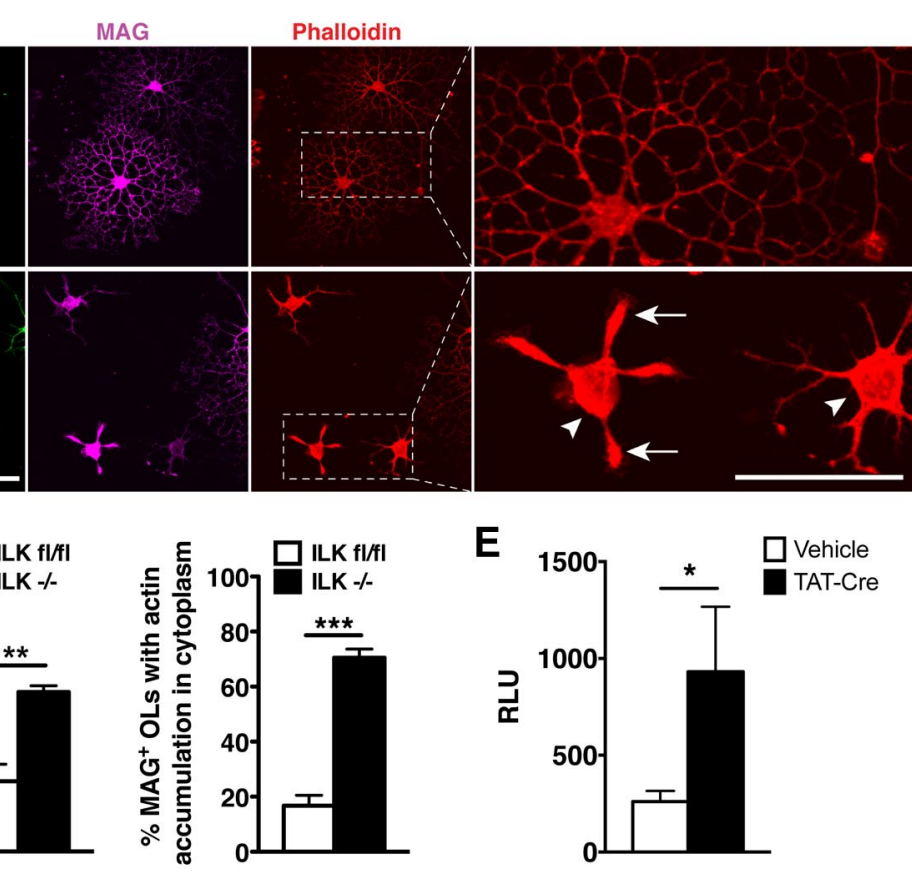

Figure 9. Abnormal actin accumulation is linked with $I / k^{-/-}$OL morphology. $\boldsymbol{A}$, Western blots performed on DIV3 and DIV6 vehicle-treated (-) or TAT-Cre-treated (Cre) primary OL lysates. Membranes were probed for ILK, Akt (p-Ser 473 and total), GSK3 $\beta$ (p-Ser 9 and total), and GAPDH as a loading control. $\boldsymbol{B}$, Densitometry analysis of relative band intensity for Western blots depicted in $\boldsymbol{A}$. C, Immunofluorescence micrographs of $/ / k^{-/-}$and $/ / k^{f / / f l}$ OLs showing actin localization with rhodamine-phalloidin staining Arrows denote filamentous actin accumulation in the process and "growth-cone" like structures while arrowheads denote cytoplasmic accumulation. $D$, Quantification of the percentage of MAG ${ }^{+v e} / I k^{-/-}$and $I / k^{f / f l} 0 \mathrm{Ls}$ with actin accumulation in the ., No significant difference. ${ }^{*} p<0.05$; ${ }^{* *} p<0.01 ;{ }^{* * *} p<0.001$ ( $\boldsymbol{B}, \boldsymbol{D}$, Student's $t$ test; $\boldsymbol{E}$, one-tailed Mann-Whitney $U$ test)

amyelination phenotype, we are presented with two general possibilities, that death of $I l k^{-1-}$ OLs permits WT cells to compensate or that $I l k^{-1-}$ OLs are developmentally delayed, requiring more time for myelination to proceed. We have eliminated the former, as there was no change in total OL number or an increase in apoptosis between the optic nerves of Ilk $c K O$ and WT mice. The second scenario, a delay in morphological maturation, therefore seems the most likely explanation, that upon ILK loss, compensation occurs through upregulation of other integrin adhesion complexes such as those containing Fyn or focal adhesion kinase. Alternatively, compensation could arise through a switch in Ln-2 directed signaling from integrin to dystroglycan, another Ln-2 receptor expressed by OLs (Colognato et al., 2007). 
A
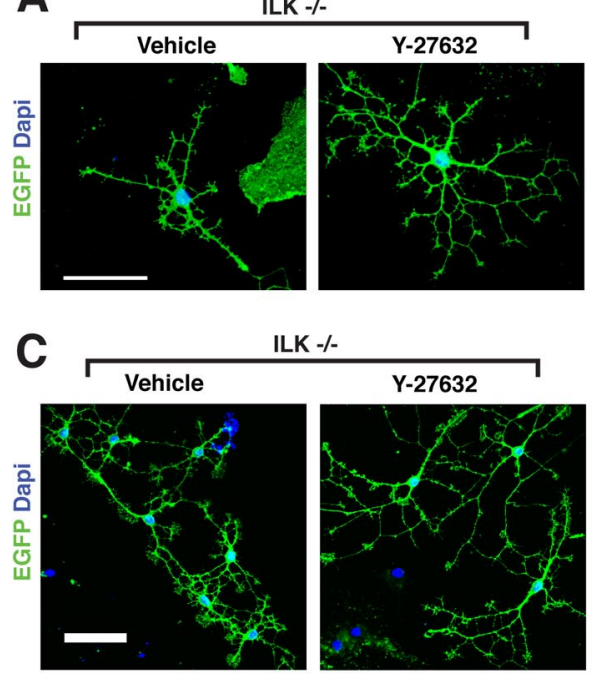

ILK $-/-$
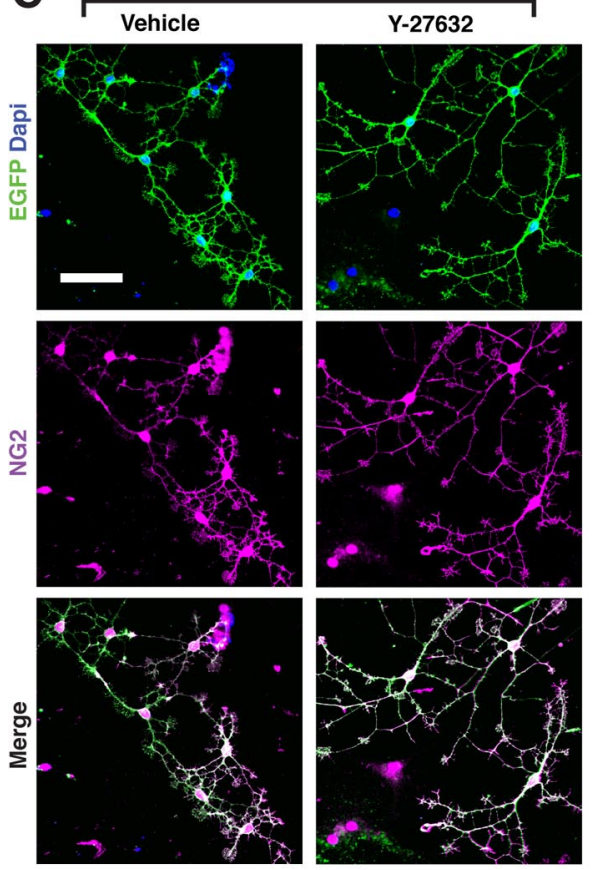
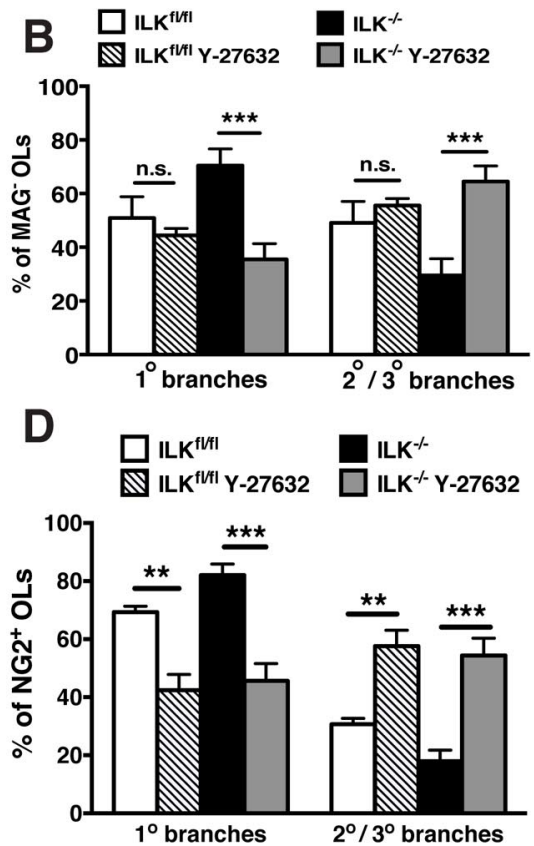

E

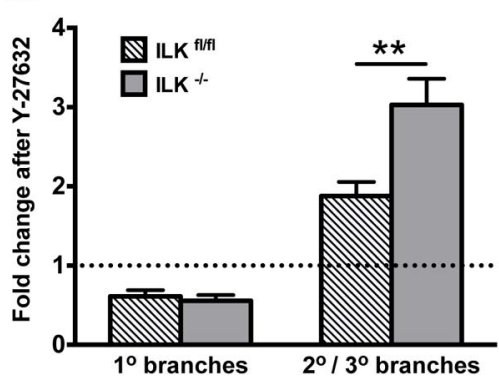

Figure 10. Administration of ROCK inhibitor Y-27632 rescues the morphology of a distinct $/ / k^{-/-}$population of $0 \mathrm{~L}$-lineage cells. $\boldsymbol{A}$, Confocal micrographs depicting the morphology of DIV6 MAG ${ }^{-v e} / 1 k^{-/-}$OLs treated with Y-27632 or vehicle control. $\boldsymbol{B}$, Morphological quantification of MAG ${ }^{-v e} / / k^{-/-}$and $I / k^{f l / f l} 0 \mathrm{Ls}$ treated with either vehicle or Y-27632. A morphological staging scheme adapted from the one depicted in Figure $4 B$ was used for this experiment. C, Confocal micrographs depicting the morphology of DIV6 NG2 ${ }^{+ \text {ve }} / / k^{-/-}$OLs treated with ROCK inhibitor Y-27632 or vehicle. D, Morphological quantification of NG2 ${ }^{+ \text {ve }}$ $I / k^{-1-}$ and $I / k^{f l / f l}$ OLs treated with either vehicle or Y-27632. E, Fold change in the proportion of $1^{\circ}$ and $2^{\circ} / 3^{\circ}$ branched NG2 $2^{+ \text {ve }}$ OPCs upon administration of $\mathrm{Y}-27632$ to $I / k^{f l / f l}$ and $/ / k^{-/-}$populations. Data represent the mean $\pm \operatorname{SEM}(n=4)$. n.S., No significant difference. ${ }^{* *} p<0.01 ;{ }^{* * *} p<0.001$ (two-way ANOVA with Bonferroni post-tests). Scale bars: $50 \mu \mathrm{m}$.

However, given the nature of our in vivo model (a single tamoxifen injection), we must also consider a paradigm wherein nonrecombined OLs outcompete $\mathrm{Ilk}^{-/-}$cells for bare axons. Two qualities lend credence to this theory. First, the myelination potential of any single OL is dependent on its ability to compete with neighboring OLs for axonal space (Chong et al., 2012). Second, OLs are plastic, able to form myelin beyond what a permissive environment would normally allow (Almeida et al., 2011; Chong et al., 2012). It is therefore reasonable to postulate compensation as occurring through endogenous "WT" OLs, an intriguing possibility when considering future development of demyelinating disease therapies.

We must also consider the nature of the Plp promoter, as it defines two separate $\mathrm{NG} 2^{+\mathrm{ve}}$ OPC populations: one that expresses PLP and one that does not (Mallon et al., 2002). While it is unknown whether these two subpopulations differ functionally, we cannot exclude the possibility that ILK has a distinct role within each. (Recall that we observe phenotypic disparity between $\mathrm{Ilk}^{-/-}$OLs in vitro.) As our PLPCreER $R^{T}$ model would target one subpopulation $\left(\mathrm{NG}^{+\mathrm{ve}} / \mathrm{PLP}^{+\mathrm{ve}}\right)$ to the exclusion of the other, the question of whether we could exacerbate (or not) the amyelination phenotype by targeting all NG2 ${ }^{\text {ve }}$ cells remains. If answered, it would provide some of the first insight into functional continuity, or lack thereof, for a member of the $\beta 1$ integrin signaling pathway between OL subgroups in vivo.

\section{ILK regulates OL actin cytoskeletal dynamics in part through RhoA}

To our surprise, the phosphorylation status of the downstream effectors Akt and GSK3 $\beta$ were unchanged following ILK loss, prompting us to instead explore the actin cytoskeleton. ILK is known to provide a bridge between environmental cues and intracellular machinery, linking the ECM and integrins to the actin cytoskeleton across a multitude of cell types and species (McDonald et al., 2008). In the OL, dynamic remodeling of the actin cytoskeleton is necessary for filopodia and lamellipodia formation, the engines driving arborization (Kim et al., 2006; Bacon et al., 2007). We therefore propose the morphological defects following ILK loss result from a breakdown in the connection between the ECM and actin cytoskeleton, ultimately leading to F-actin accumulation/disorganization and subsequent process outgrowth failure.

As ILK regulates actin dynamics indirectly through recruitment of focal adhesion complexes (Legate et al., 2006), the observed perturbation in F-actin is most likely an outcome of ILK complex dissolution. Under normal conditions, ILKassembled complexes are capable of both direct $\mathrm{F}$-actin binding and indirect actin remodeling, the latter an event largely regulated by the small Rho GTPase family (Wickström et al., 2010). With relevance to our work, ILK-directed focal adhesions act as checkpoints for RhoA and its effector ROCK, with loss of ILK or $\alpha$-parvin leading to increased pathway activity and subsequent F-actin disorganization (Kogata et al., 2009; Montanez et al., 2009; Pereira et al., 2009). Upregulation of RhoA signaling in neurons manifests as cortical actin accumulation with concomitant inhibition of neurite extension (Yamaguchi et al., 2001), and in OLs as reduction in process outgrowth and branching (Liang et al., 2004; Rajasekharan et al., 2010, 2009; Wang et al., 2012). We observed an increase in active RhoA levels following ILK depletion in our OL cultures. When treated with the ROCK inhibitor Y-27632, $\mathrm{MAG}^{+\mathrm{ve}} I l k^{-/-}$OLs did not respond as expected, with no increase in morphological complexity. Instead, NG2 ${ }^{+\mathrm{ve}} / \mathrm{MAG}^{-\mathrm{ve}}$ $I l k^{-1-}$ OLs displayed a surge in arbor sprouting. The results suggest ILK regulation of the RhoA/ROCK pathway is limited to a distinct OL subpopulation, specifically that which is transitioning from a precursor to immature OL state.

It was surprising to note no change in morphological complexity of $\mathrm{MAG}^{+\mathrm{ve}} \mathrm{Ilk}^{-/-}$OLs upon ROCK inhibition. The controlled manipulation of the actin cytoskeleton by ILK within this 
cell population must occur through pathways independent of Rho/ROCK signaling. One possibility is deactivation of the ILK-regulated neural Wiskott-Aldrich syndrome protein (N-WASP)/Arp2/3 complex (mediators of actin polymerization), as N-WASP disruption negatively impacts OL process outgrowth (Bacon et al., 2007). In addition, ILK is required for $\alpha$-parvin/ $\beta$-parvin stabilization and paxillin localization, both of which bind F-actin directly (Attwell et al., 2003; Legate et al., 2006). Therefore, loss of ILK could lead to F-actin/integrin/ECM uncoupling, which may explain the observed OL morphological defects. Additionally, $I l k^{-1-}$ OLs are characterized by an inability to extend myelin-like membranes. While this is possibly due to cytoskeletal defects, our results following ROCK inhibition (improved branching but not membrane formation) suggest other pathways are at play, implying that ILK's governance of OL process outgrowth and myelin membrane formation occur through separate mechanisms.

Through our work, we have begun to dissect ILK-directed signaling pathways overseeing unique aspects of OL development. Precisely which downstream targets potentiate ILK's role in cytoskeletal reorganization and how their actions differ at varying stages of OL differentiation remain intriguing questions for the future.

\section{References}

Almeida RG, Czopka T, Ffrench-Constant C, Lyons DA (2011) Individual axons regulate the myelinating potential of single oligodendrocytes in vivo. Development 138:4443-4450. CrossRef Medline

Attwell S, Mills J, Troussard A, Wu C, Dedhar S (2003) Integration of cell attachment, cytoskeletal localization, and signaling by integrin-linked kinase (ILK), CH-ILKBP, and the tumor suppressor PTEN. Mol Biol Cell 14:4813-4825. CrossRef Medline

Bacon C, Lakics V, Machesky L, Rumsby M (2007) N-WASP regulates extension of filopodia and processes by oligodendrocyte progenitors, oligodendrocytes, and Schwann cells-implications for axon ensheathment at myelination. Glia 55:844-858. CrossRef Medline

Barros CS, Nguyen T, Spencer KS, Nishiyama A, Colognato H, Müller U (2009) Betal integrins are required for normal CNS myelination and promote AKT-dependent myelin outgrowth. Development 136: 2717-2724. CrossRef Medline

Benninger Y, Colognato H, Thurnherr T, Franklin RJ, Leone DP, Atanasoski S, Nave KA, Ffrench-Constant C, Suter U, Relvas JB (2006) Beta1integrin signaling mediates premyelinating oligodendrocyte survival but is not required for CNS myelination and remyelination. J Neurosci 26: 7665-7673. CrossRef Medline

Brakebusch C, Fässler R (2003) The integrin-actin connection, an eternal love affair. EMBO J 22:2324-2333.

Butt AM, Berry M (2000) Oligodendrocytes and the control of myelination in vivo: new insights from the rat anterior medullary velum. J of neuroscience research 59:477-488. CrossRef

Buttery PC, ffrench-Constant C (1999) Laminin-2/integrin interactions enhance myelin membrane formation by oligodendrocytes. Mol Cell Neurosci 14:199-212. CrossRef Medline

Câmara J, Wang Z, Nunes-Fonseca C, Friedman HC, Grove M, Sherman DL, Komiyama NH, Grant SG, Brophy PJ, Peterson A, ffrench-Constant C (2009) Integrin-mediated axoglial interactions initiate myelination in the central nervous system. The J of cell biology. 185:699-712. CrossRef
Chang A, Tourtellotte WW, Rudick R, Trapp BD (2002) Premyelinating oligodendrocytes in chronic lesions of multiple sclerosis. New Eng J Med 346:165-173. CrossRef Medline

Chong SY, Rosenberg SS, Fancy SP, Zhao C, Shen YA, Hahn AT, McGee AW, Xu X, Zheng B, Zhang LI, Rowitch DH, Franklin RJ, Lu QR, Chan JR (2012) Neurite outgrowth inhibitor Nogo-A establishes spatial segregation and extent of oligodendrocyte myelination. Proc Natl Acad Sci U S A 109:1299-1304. CrossRef Medline

Chun SJ, Rasband MN, Sidman RL, Habib AA, Vartanian T (2003) Integrinlinked kinase is required for laminin-2-induced oligodendrocyte cell spreading and CNS myelination. J Cell Biol 163:397-408. CrossRef Medline

Colognato H, Baron W, Avellana-Adalid V, Relvas JB, Baron-Van Evercooren A, Georges-Labouesse E, ffrench-Constant C (2002) CNS integrins switch growth factor signalling to promote target-dependent survival. Nat Cell Biol 4:833-841. CrossRef Medline

Colognato H, Galvin J, Wang Z, Relucio J, Nguyen T, Harrison D, Yurchenco PD, Ffrench-Constant C (2007) Identification of dystroglycan as a second laminin receptor in oligodendrocytes, with a role in myelination. Development 134:1723-1736. CrossRef Medline

Doerflinger NH, Macklin WB, Popko B (2003) Inducible site-specific recombination in myelinating cells. Genesis 35:63-72. CrossRef Medline

Forrest AD, Beggs HE, Reichardt LF, Dupree JL, Colello RJ, Fuss B (2009) Focal adhesion kinase (FAK): A regulator of CNS myelination. J Neurosci Res 87:3456-3464. CrossRef Medline

Govek EE, Newey SE, Van Aelst L (2005) The role of the Rho GTPases in neuronal development. Gene Dev 19:1-49. CrossRef Medline

Graness A, Giehl K, Goppelt-Struebe M (2006) Differential involvement of the integrin-linked kinase (ILK) in RhoA-dependent rearrangement of F-actin fibers and induction of connective tissue growth factor (CTGF). Cell Signal 18:433-440. CrossRef Medline

Hannigan GE, Leung-Hagesteijn C, Fitz-Gibbon L, Coppolino MG, Radeva G, Filmus J, Bell JC, Dedhar S (1996) Regulation of cell adhesion and anchorage-dependent growth by a new b1-integrin-linked protein kinase. Nature 379:91-96. CrossRef Medline

Hannigan GE, McDonald PC, Walsh MP, Dedhar S (2011) Integrin-linked kinase: not so "pseudo" after all. Oncogene 30:4375-4385. CrossRef Medline

Kim HJ, DiBernardo AB, Sloane JA, Rasband MN, Solomon D, Kosaras B, Kwak SP, Vartanian TK (2006) WAVE1 is required for oligodendrocyte 
morphogenesis and normal CNS myelination. J Neurosci 26:5849-5859. CrossRef Medline

Kogata N, Tribe RM, Fässler R, Way M, Adams RH (2009) Integrin-linked kinase controls vascular wall formation by negatively regulating Rho/ ROCK-mediated vascular smooth muscle cell contraction. Gene Dev 23: 2278-2283. CrossRef Medline

Lee KK, de Repentigny Y, Saulnier R, Rippstein P, Macklin WB, Kothary R (2006) Dominant-negative beta1 integrin mice have region-specific myelin defects accompanied by alterations in MAPK activity. Glia 53:836844. CrossRef Medline

Legate KR, Montañez E, Kudlacek O, Fässler R (2006) ILK, PINCH and parvin: the tIPP of integrin signalling. Nat Rev Mol Cell Biol 7:20-31.

Liang X, Draghi NA, Resh MD (2004) Signaling from integrins to Fyn to Rho family GTPases regulates morphologic differentiation of oligodendrocytes. J Neurosci 24:7140-7149. CrossRef Medline

Mallon BS, Shick HE, Kidd GJ, Macklin WB (2002) Proteolipid promoter activity distinguishes two populations of NG2-positive cells throughout neonatal cortical development. J Neurosci 22:876-885. Medline

McDonald PC, Fielding AB, Dedhar S (2008) Integrin-linked kinase-essential roles in physiology and cancer biology. J Cell Sci 121:3121-3132. CrossRef Medline

Montanez E, Wickström SA, Altstätter J, Chu H, Fässler R (2009) Alphaparvin controls vascular mural cell recruitment to vessel wall by regulating RhoA/ROCK signalling. EMBO J 28:3132-3144. CrossRef Medline

Muzumdar MD, Tasic B, Miyamichi K, Li L, Luo L (2007) A global doublefluorescent Cre reporter mouse. Genesis 45:593-605. CrossRef Medline

O’Meara RW, Michalski JP, Kothary R (2011a) Integrin signaling in oligodendrocytes and its importance in CNS myelination. J Signal Transduct 2011:354091. Medline

O’Meara RW, Ryan SD, Colognato H, Kothary R (2011b) Derivation of enriched oligodendrocyte cultures and oligodendrocyte/neuron myelinating co-cultures from post-natal murine tissues. J Vis Exp 54:e3324.

Peitz M, Pfannkuche K, Rajewsky K, Edenhofer F (2002) Ability of the hydrophobic FGF and basic TAT peptides to promote cellular uptake of recombinant Cre recombinase: a tool for efficient genetic engineering of mammalian genomes. Proc Natl Acad Sci U S A 99:4489-4494. CrossRef Medline

Pereira JA, Benninger Y, Baumann R, Gonçalves AF, Ozçelik M, Thurnherr T, Tricaud N, Meijer D, Fässler R, Suter U, Relvas JB (2009) Integrin- linked kinase is required for radial sorting of axons and Schwann cell remyelination in the peripheral nervous system. J Cell Biol 185:147-161. CrossRef Medline

Rajasekharan S, Baker KA, Horn KE, Jarjour AA, Antel JP, Kennedy TE (2009) Netrin 1 and Dcc regulate oligodendrocyte process branching and membrane extension via Fyn and RhoA. Development 136:415-426. CrossRef Medline

Rajasekharan S, Bin JM, Antel JP, Kennedy TE (2010) A central role for RhoA during oligodendroglial maturation in the switch from netrin-1mediated chemorepulsion to process elaboration. J Neurochem 113: 1589-1597. Medline

Relvas JB, Setzu A, Baron W, Buttery PC, LaFlamme SE, Franklin RJ, ffrenchConstant C (2001) Expression of dominant-negative and chimeric subunits reveals an essential role for betal integrin during myelination. Curr Biol 11:1039-1043. CrossRef Medline

Rosenberger G, Jantke I, Gal A, Kutsche K (2003) Interaction of alphaPIX (ARHGEF6) with beta-parvin (PARVB) suggests an involvement of alphaPIX in integrin-mediated signaling. Hum Mol Genet 12:155-167. CrossRef Medline

Terpstra L, Prud'homme J, Arabian A, Takeda S, Karsenty G, Dedhar S, St-Arnaud R (2003) Reduced chondrocyte proliferation and chondrodysplasia in mice lacking the integrin-linked kinase in chondrocytes. J Cell Biol 162:139-148. CrossRef Medline

Thomson CE, Vouyiouklis DA, Barrie JA, Wease KN, Montague P (2005) Plp gene regulation in the developing murine optic nerve: correlation with oligodendroglial process alignment along the axons. Dev Neurosci 27:27-36. CrossRef Medline

Wang H, Rusielewicz T, Tewari A, Leitman EM, Einheber S, MelendezVasquez CV (2012) Myosin II is a negative regulator of oligodendrocyte morphological differentiation. J Neurosci Res 90:1547-1556. CrossRef Medline

Wickström SA, Lange A, Montanez E, Fässler R (2010) The ILK/PINCH/ parvin complex: the kinase is dead, long live the pseudokinase! EMBO J 29:281-291.

Yamaguchi Y, Katoh H, Yasui H, Mori K, Negishi M (2001) RhoA inhibits the nerve growth factor-induced Racl activation through Rho-associated kinase-dependent pathway. J Biol Chem 276:18977-18983. CrossRef Medline 